\title{
Tailoring active sites of iron-nitrogen-carbon catalysts for oxygen reduction in alkaline environment: Effect of nitrogen-based organic precursor and pyrolysis atmosphere
}

\author{
Williane da Silva Freitas a, Alessandra D’Epifanio a, Valerio C.A. Ficca ${ }^{a}$, Ernesto Placidi ${ }^{\text {b,c }}$, \\ Fabrizio Arciprete ${ }^{c}$, Barbara Mecheri ${ }^{\mathrm{a}, *}$
}

a Department of Chemical Science and Technologies, University of Rome Tor Vergata, Via della Ricerca Scientifica, Rome 00133, Italy

${ }^{\mathrm{b}}$ Department of Physics, Sapienza University of Rome, Piazzale Aldo Moro 2, Rome 00185, Italy

${ }^{\mathrm{c}}$ Department of Physics, University of Rome Tor Vergata, Via della Ricerca Scientifica, Rome 00133, Italy

\section{A R T I C L E I N F O}

\section{Article history:}

Received 15 April 2021

Revised 18 June 2021

Accepted 6 July 2021

Available online 16 July 2021

\section{Keywords:}

Oxygen reduction reaction

Alkaline $\mathrm{pH}$

Iron-nitrogen-carbon catalysts

Rotating ring disk electrode

Surface chemistry

\begin{abstract}
A B S T R A C T
Fe-N-C catalysts were synthesized from a nitrogen and iron wet impregnation of carbon black pearls followed by pyrolysis steps. Three different nitrogen sources (dopamine, imidazole and benzimidazole), and two different pyrolysis atmospheres $\left(\mathrm{Ar}\right.$ and $\mathrm{NH}_{3}$ ) were used. The obtained materials were characterized in terms of structure, morphology, surface chemistry, and electrochemical properties. Electrodes with a high porosity and accessible active sites were obtained tailoring the synthesis parameters, as indicated by Raman and X-ray photoelectron spectroscopies, and cyclic voltammetry with rotating ring disk electrode. Pyrolysis under ammonia atmosphere led to high electrochemical active surface area (ECSA) and the use of imidazole as nitrogen-rich organic precursor improved oxygen reduction reaction (ORR) activity in alkaline $\mathrm{pH}$. This can be ascribed to the modification of surface chemistry of the electrocatalysts triggered by the N-rich organic precursor and pyrolysis atmosphere. The catalyst obtained by using imidazole and pyrolyzed in $\mathrm{NH}_{3}$ had a variety of iron-, oxygen- and nitrogen-functional groups, nitrogen being mainly distributed in imine-, pyridinic- and pyrrolic-N. In addition, durability tests showed a stable ECSA and ORR activity after cycling of the prepared electrocatalysts outperforming durability of Pt-based materials in alkaline environment and indicating applicability in anion exchange membrane fuel cells.
\end{abstract}

() 2021 Elsevier Ltd. All rights reserved.

\section{Introduction}

High energy demand faced with the urgent need for a transition towards a circular economy require strategies to reduce the environmental impact generated by the transport and industrial sectors, which account for two thirds of global $\mathrm{CO}_{2}$ emissions [1]. Hydrogen is a central element in meeting the net-zero emissions target, for it can be used as a fuel or as energy carrier and storage, leading to many possible applications across industry, power, and transport sectors. Compressed $\mathrm{H}_{2}$ or hydrogen generated using steam reforming of hydrocarbons or coal gasification finds application for large energy demand such as vehicle applications. However, these methods are unsuitable for portable devices and in the absence of enough storage space in small mobile devices [2]. Chemical hydrides, including metal-boron hydrides, offer sustainable hydrogen storage systems, being able of local hydrogen

\footnotetext{
* Corresponding author.

E-mail address: barbara.mecheri@uniroma2.it (B. Mecheri).
}

generation via pyrolysis or hydrolysis [3-5]. Hydrogen-fed anion exchange membrane fuel cells (AEMFCs), which use a variety of chemicals as fuel for power generation, in particular hydrogen, are therefore very promising for decarbonization of the transportation sector [6]. As compared to the other families of fuel cells, AEMFC offers the possibility of using a less expensive chemistry for materials synthesis thus reducing device cost [7]. However, the slow kinetics of oxygen reduction reaction (ORR) at the cathode side is one of the feature that significantly hampers AEMFC performance, and Platinum-Group-Metal (PGM) catalysts are still the state-ofthe-art materials to accelerate ORR [8-10]. PGM catalysts are not only responsible for more of $50 \%$ of the fuel stack total cost [11], but are also prone to dissolution, and are easily poisoned with the presence of contaminants, such as $\mathrm{CO}, \mathrm{H}_{2} \mathrm{~S}$ and $\mathrm{NH}_{3}$ [12], leading to low AMEFC durability.

Many research efforts have thus been devoted to the development of PGM-free catalysts and transition metal-nitrogen-carbon (M-N-C) materials have been identified among the most promising alternatives for oxygen reduction in AEMFCs [13-16]. In these ma- 
terials, nitrogen and transition metals ions, such as Fe, Co and Mn (II), are used as co-dopant in carbon nanostructures to form active sites with the metal center coordinated by $\mathrm{N}_{\mathrm{x}}-\mathrm{C}$ groups, in which $x$ represents the number of coordination for the $\mathrm{N}$-functionalities and is correlated with the catalytic performance [17]. Previous reports have demonstrated that $\mathrm{M}-\mathrm{N}_{\mathrm{x}}-\mathrm{C}$ sites in the equatorial plane have a high ORR activity, compared to $\mathrm{M}-\mathrm{N}_{\mathrm{x}}-\mathrm{C}$ moieties at the edges of a carbon matrix $[18,19]$. As far as nitrogen atom speciation is concerned, pyrrolic and pyridinic nitrogen are known to be the most active species towards ORR: in particular, a higher content of pyridinic nitrogen in a $\mathrm{M}-\mathrm{N}_{\mathrm{x}}-\mathrm{C}$ moiety promotes a shift of ORR onset potential to more positive values. By contrast, even if the role of graphitic or quaternary- $\mathrm{N}$ is still under discussion, it has been suggested that higher graphitic nitrogen content led to a conversion of ORR reaction mechanism to a four-electron pathway $[20,21]$. Carbon matrix also plays an important role on ORR activity because a porous structure enhances the accessibility of active sites in $\mathrm{M}-\mathrm{N}_{\mathrm{x}}-\mathrm{C}$ moieties. Macro and mesopores are believed to assist the mass transport of species involved in the ORR, while micropores typically host the $\mathrm{M}-\mathrm{N}_{\mathrm{x}}-\mathrm{C}$ sites. Therefore, ORR activity can be improved combining a carbon matrix with high distribution of meso/macropores and high density of active sites [22-25].

$\mathrm{M}-\mathrm{N}_{\mathrm{X}}-\mathrm{C}$ catalysts are usually synthesized via pyrolysis of metal and nitrogen precursors either adsorbed or impregnated onto a carbon support [26,27] or through the pyrolysis of a single precursor of metal, nitrogen, and carbon [24,28-34]. Pyrolysis temperatures between 800 and $900{ }^{\circ} \mathrm{C}$ are generally used to obtain $\mathrm{M}-\mathrm{N}_{\mathrm{X}}-$ C active sites with high ORR activity in alkaline media [12,35-37]. Despite the progress made, there are still numerous challenges before PGM-free catalysts become viable for AEMFC technology, including catalysts stability. In fact, the performance and stability of a AEMFC operating with PGM-free at both the anode and cathode are still limited $[38,39]$. Also, there is a lack in terms of durability studies investigating electrocatalyst degradation during AEMFC operation $[40,41]$.

In this scenario we report here a facile synthesis strategy based on the combination of a high surface area conductive support with nitrogen-containing organic precursors and an iron salt. Through the investigation of two pyrolysis atmospheres and different nitrogen-rich precursors, insights of the effect of morphology and chemical surface of the obtained Fe-N-C catalysts on ORR activity have been achieved. Electrocatalysts with high surface area, high ORR activity with a direct $4 \mathrm{e}^{-}$mechanism were obtained by tailoring the synthesis parameters, outperforming platinum-based materials in terms of durability over cycling in alkaline $\mathrm{pH}$.

\section{Experimental section}

\subsection{Materials}

Dopamine hydrochloride (98.0\%), iron (II) acetate (> 98.0\%), nitric acid ( $\geq 65.0 \%)$, N,N-Dimethylformamide (99.8\%) and Nafion solution (5 wt. \% in lower aliphatic alcohols and water, 15-20\%) were purchased from Sigma-Aldrich. Imidazole (>98.0\%) and benzimidazole (> 98.0\%) from TCI, and Carbon Black Pearls 2000 (BP) were supplied by CABOT. Platinum, nominally $40 \%$ on carbon black $(\mathrm{Pt} / \mathrm{C})$ was purchased by Alfa Aesar. Millipore water (Merk, $18.2 \mathrm{M} \Omega \mathrm{cm}$ ) was used for materials preparation and experiments.

\subsection{Preparation of catalysts}

\subsubsection{Treatment of carbon support}

Carbon black pearls ( $1.0 \mathrm{~g})$ was dispersed in concentrated nitric acid $(40 \mathrm{~mL})$ using an ultrasonic bath for $15 \mathrm{~min}$. The obtained dispersion was kept under stirring and reflux at $90{ }^{\circ} \mathrm{C}$ for $16 \mathrm{~h}$. The material was collected by centrifugation and washed several times with distilled water, using a filtration system, until neutral $\mathrm{pH}$ was reached. After that, it was dried in an oven at $70{ }^{\circ} \mathrm{C}$ overnight and then grounded with an agate mortar and pestle. Treated carbon black pearls was labeled as BP.

\subsection{2. $\mathrm{Fe}$ - and $\mathrm{N}$ - functionalization of carbon support}

BP (400 mg) were dispersed in $160 \mathrm{ml}$ of an acetone/water (10/90 wt.\%) mixture by $15 \mathrm{~min}$ sonication dat room temperature. An organic precursor (400 mg), either Dopamine hydrochloride (DP) or Imidazole (Im) or Benzimidazole (BZ), was added to the suspension and stirred for $5 \mathrm{~min}$. After that, iron (II) acetate $(0.498 \mathrm{mg}$ ) was added to a $0.2 \mathrm{wt}$. \% content of iron (II) in the catalyst. The dispersion was then kept under magnetic stirring for $2 \mathrm{~h}$ at room temperature. The precursor was dried in an oven at $70{ }^{\circ} \mathrm{C}$ overnight and the powder grounded with an agate mortar and pestle. The obtained materials were labeled as BP-DP-Fe, BPIm-Fe, and BP-BZ-Fe (Table S1). The catalyst precursor (400 mg) was placed in a $\mathrm{Al}_{2} \mathrm{O}_{3}$-tube $(2.0 \mathrm{~cm}$ diameter, $69 \mathrm{~cm}$ length) furnace (Forni De Marco, Italy) purged with either $\mathrm{Ar}$ or anhydrous $\mathrm{NH}_{3}$ for $20 \mathrm{~min}$ at a flow of $200 \mathrm{sccm}$ and room temperature. The material was thermally treated in two heating steps: the first one at $400{ }^{\circ} \mathrm{C}$ for $1 \mathrm{~h}$ (heating rate of $20{ }^{\circ} \mathrm{C} \mathrm{min}-1$ ), and the second one at $800{ }^{\circ} \mathrm{C}$ for $1 \mathrm{~h}$ (heating rate of $25^{\circ} \mathrm{C} \mathrm{min}-1$ ). After pyrolysis, the catalyst was grounded with an agate mortar and pestle. The samples obtained by pyrolysis in argon atmosphere were labeled as (BP-DP-Fe-Ar, BP-Im-Fe-Ar, BP-BZ-Fe-Ar), while the samples obtained by pyrolysis in $\mathrm{NH}_{3}$ atmosphere were labeled as BPDP-Fe- $\mathrm{NH}_{3}, \mathrm{BP}-\mathrm{Im}-\mathrm{Fe}-\mathrm{NH}_{3}, \mathrm{BP}-\mathrm{BZ}-\mathrm{Fe}-\mathrm{NH}_{3}$, as summarized in Table S1.

\subsection{Materials characterization}

\subsubsection{Physicochemical characterization}

Thermogravimetric analysis (TGA) was performed by using a thermogravimetric analyzer TGA/DSC1 Star System (Mettler Toledo) working under a $\mathrm{N}_{2}$ flow between 25 to $800{ }^{\circ} \mathrm{C}$, with a heating rate of $5{ }^{\circ} \mathrm{C} \mathrm{min}^{-1}$. The materials were held in a platinum sample holder with a cover having one vent central hole. Powder X-ray diffraction (XRD) patterns were recorded using Philips PW1730 diffractometer with $\mathrm{Cu} \mathrm{K}_{\alpha}$ radiation $(\lambda=1.5406 \AA)$. Micrographs were obtained using a Leo Supra 35 field-emission scanning electron microscope (Carl Zeiss, Oberkochen, Germany). X-ray photoelectron spectroscopy (XPS) was performed using an Omicron DAR $400 \mathrm{Al} / \mathrm{Mg} \mathrm{K} \alpha$ non-monochromatized X-ray source, and a VG-CLAM2 electron spectrometer, working with a pass energy of $20 \mathrm{eV}$. The fitted peaks for $\mathrm{C} 1 \mathrm{~s}, \mathrm{~N} 1 \mathrm{~s}$ and $\mathrm{Fe} 2 \mathrm{p}$ spectra were obtained by deconvolution using KolXPD Software with a Voigtian (combining weighted Gaussian and Lorentzian) peak fitting, Shirley and/or linear background and Doniach-Sunjic convoluted with a gaussian for graphitic $\mathrm{sp}^{2}$-hybridized peak. Raman spectroscopy was performed using a DXR Raman Microscope (thermo Scientific) using a laser excitation wavelength of $532 \mathrm{~nm}$ with a $10 \mathrm{X}$ objective, with the laser power maintained at $0.1 \mathrm{~mW}$. Experimental data were fitted using KolXPD Software with a Voigtian peak fitting [42-44].

\subsubsection{Electrochemical characterization}

Electrochemical tests were performed using a standard three electrode cell: a rotating ring disk electrode (RRDE-AFE6R2GCPT, Pine Research Instrumentation) was used as working electrode (WE), whereas a platinum wire (Amel 805/SPG/12) and saturated calomel electrode (SCE, Amel 303/SCG/12) as counter and reference electrodes, respectively. The measurements were recorded with a VMP3 Potentiostat (Bio Logic Science Instruments) controlled by computer through EC-Lab V10.18 software. The potential values for all electrochemical tests were measured vs. SCE and converted to 
the reversible hydrogen electrode (RHE). The WE was modified by depositing a catalyst ink as follows: $5.0 \mathrm{mg}$ of catalyst were dispersed in $455 \mathrm{~mL}$ of a Nafion/DMF solution ( $0.5 \mathrm{wt} . \%$, which preparation is described in detail in the supporting material), and the suspension was ultrasonicated for $1 \mathrm{~h}$ at a room temperature. The ink (5 $\mu \mathrm{L}$ for RRDE) was dropped onto the glassy carbon disk of the WE to a catalyst loading of $0.23 \mathrm{mgcm}^{-2}$, and dried in a convection oven at $40{ }^{\circ} \mathrm{C}$ for $6 \mathrm{~min}$. A Pt/C ink was also prepared (to a $40 \mu \mathrm{gcm}^{-2} \mathrm{Pt} / \mathrm{C}$ loading and $16 \mu \mathrm{gcm}^{-2}$ Pt loading) and taken as control [45]. The electrodes were placed in a $\mathrm{KOH} \mathrm{0.1} \mathrm{M} \mathrm{electrolyte}$ solution, purged with $\mathrm{N}_{2}$ for $20 \mathrm{~min}$, and before acquiring electrochemical measurements the electrode surface was cleaned as described in the supporting material and activated by cyclic voltammetry $(\mathrm{CV})$ in a potential window $1.2-0.3 \mathrm{~V}$ vs. RHE at a scan rate of $500 \mathrm{mVs}^{-1}$ (200 cycles). The ohmic resistance of the systems was also evaluated by $i \mathrm{R}$ determination and compensation by impedance spectroscopy [46]. An additional catalyst activation of 100 cycles at the same scan rate, was used for the measurements in $\mathrm{O}_{2}$-saturated electrolyte after purging the system with the gas for at least $20 \mathrm{~min}$.

Cyclic voltammetry (CV) experiments using a RDE in static configuration were performed to investigate ORR activity and estimate the electrochemical active surface area (ECSA) of the Fe-N-C catalysts. Gravimetric capacitance $\left(\mathrm{C}_{\text {grav. }}\right)$ was calculated by integrating capacitive current from CV curves at a scan rate of $5 \mathrm{mVs}^{-1}$, in nitrogen saturated electrolyte over a $0.9 \mathrm{~V} v s$. RHE potential window, according to Eq. (1) [47]:

$$
\mathrm{C}_{\mathrm{Grav} .}=\frac{\int I d V}{2 \mathrm{~m} v \Delta \mathrm{V}}
$$

where $I$, is the current $(A), \Delta V$ is the potential window $(V), \mathrm{m}$ is the catalyst mass on the electrode $(g)$, and $v\left(\mathrm{Vs}^{-1}\right)$ is the potential scan rate. Then, ECSA was estimated according to Eq. (2) $[48,49]$, assuming a capacitance per surface area $\left(C_{s}\right)$ of $0.2 \mathrm{Fm}^{-2}$ [50-52] for the synthesized PGM-free catalysts.

$\mathrm{ECSA}=\mathrm{C}_{\mathrm{Grav} .} / \mathrm{C}_{\mathrm{s}}$

ECSA values for Pt/C was calculated by integrating the CV (Fig. S8a) in the hydrogen underpotential deposition region, assuming a monolayer hydrogen charge of $210 \mu \mathrm{Ccm}^{-2}$ [53,54].

Linear sweep voltammetry (LSV) with rotating ring disk electrode (RRDE) experiments were performed at scan rate of $5 \mathrm{mVs}^{-1}$ and rotation speed of $1600 \mathrm{rpm}$ from 1.2 to $0.3 \mathrm{~V}$ vs. RHE, with the Pt ring polarized at $1.2 \mathrm{~V} v$ s. RHE [55]. Disk and ring currents were background corrected by subtracting the capacitive current measured in $\mathrm{N}_{2}$-saturated electrolyte and the potentials reported were $i \mathrm{R}$-compensated. The number of electrons transferred $(n)$ and hydroperoxide anion $\left(\mathrm{HO}_{2}^{-}\right)$produced, were calculated according to Eqs. (3) and (4), where $N$ is the ring collection efficiency (0.38).

$$
\begin{aligned}
& \mathrm{n}=\frac{4 \times\left|\mathrm{I}_{\text {Disk }}\right|}{\left|\mathrm{I}_{\text {Disk }}\right|+\left|\mathrm{I}_{\text {Ring }} / \mathrm{N}\right|} \\
& \mathrm{HO}_{2}^{-}(\%)=200 \frac{\left|\mathrm{I}_{\text {Ring }} / \mathrm{N}\right|}{\left|\mathrm{I}_{\text {Disk }}\right|+\left|\mathrm{I}_{\text {Ring }} / \mathrm{N}\right|}
\end{aligned}
$$

LSV-RRDE experiments were also used to draw Tafel plots, by plotting $i \mathrm{R}$-corrected potential values as a function of the logarithm of the kinetic current density as described in the Eq. (5) [56,57]:

$\mathrm{E}=\mathrm{E}^{0}+\frac{2.303 \mathrm{RT}}{\alpha_{\mathrm{c}} \mathrm{F}} \log \mathrm{J}_{0}-\frac{2.303 \mathrm{RT}}{\alpha_{\mathrm{c}} \mathrm{F}} \log \mathrm{J}_{\mathrm{k}}$

where $E$ is the $i$-corrected electrode potential, $\mathrm{E}^{0}$ is $1.23 \mathrm{~V}, R$ the universal gas constant $\left(8.314 \mathrm{~J} \mathrm{~mol}^{-1} \mathrm{~K}^{-1}\right), T$ the working temperature $(298.15 \mathrm{~K}), F$ the Faraday constant $\left(96487 \mathrm{C} \mathrm{mol}^{-1}\right), \alpha_{\mathrm{c}}$ is the cathodic transfer coefficient, $J_{0}$ the exchange current density, and
$J_{\mathrm{k}}$ the kinetic current density obtained by the Eq. (6):

$\mathrm{J}_{\mathrm{k}}(\mathrm{E})=\left|\frac{\mathrm{J}_{\mathrm{D}} \times \mathrm{J}(\mathrm{E})}{\left(\mathrm{J}_{\mathrm{D}}-\mathrm{J}(\mathrm{E})\right)}\right|$

where $J_{\mathrm{D}}$ is the diffusion-limited current (extrapolated at $0.5 \mathrm{~V} v s$. RHE potential), and $J(E)$, the measured background-subtracted current density [58].

EIS spectra were acquired under hydrodynamic conditions (1600 rpm as electrode rotation rate) at three different potential values E1 (onset potential), E2 (half-wave potential), E3 (near limiting current), over a frequency range of $50 \mathrm{mHz}-100 \mathrm{kHz}$ with an amplitude of $10 \mathrm{mV}$. EC-Lab ZFit impedance fitting tools (BioLogic SAS) were used for modeling EIS spectra.

Durability tests were carried out according to a start-stop cycling protocol proposed by the Fuel Cell Commercialization Conference of Japan (FCCJ).[59] The experiments were performed by recording $\mathrm{CV}$ in $\mathrm{N}_{2}$-saturated electrolyte to evaluate the ECSA changes during 7000 cycles at a scan rate of $500 \mathrm{mVs}^{-1}$; CV curves shown in the text refer to cycles n. $1,200,400,600,800,1000$ and multiples of 1000 over the remaining 6000 cycles and were recorded at a scan rate of $5 \mathrm{mVs}^{-1}$. CV were also recorded in $\mathrm{O}_{2}$ saturated electrolyte to evaluate the ORR activity changes during 7000 cycles at a scan rate of $500 \mathrm{mVs}^{-1}$ with same protocol above described for $\mathrm{CVs}$ in $\mathrm{N}_{2}$-saturated electrolyte.

\section{Results and discussion}

Two series of catalysts were prepared as described in Section 2.2 .2 by using iron acetate as metal source, carbon black pearls as carbon support and three different nitrogen-rich organic precursors (dopamine, imidazole and benzimidazole); two different pyrolysis atmospheres (argon and anhydrous ammonia gas) were used for obtaining the Fe-N-C catalysts, which were labeled as indicated in Table S1. Morphology of Fe-N-C catalysts was investigated by SEM analysis (Fig. S1) indicating a general porous structure of heterogeneous aspect for all samples; in particular, the pyrolysis in ammonia atmosphere led to a more homogeneous morphology, as an effect of the gas to improve surface area of the carbon matrix during the heat treatment [60]. Thermogravimetric (TG) analysis was used to get information of the thermal properties of the prepared materials (Fig. S2 and Table S2). BP-DP-Fe showed the highest residual mass at $800{ }^{\circ} \mathrm{C}$, in good agreement with the highest residual mass of dopamine precursors as compared to imidazole and benzimidazole. However, it is worth noting that, although the residual mass for imidazole and benzimidazole precursors was the same ( 1 wt.\%) the higher residual mass (55 wt. $\%$ ) observed for BP-Im-Fe as compared to BP-BZ-Fe (47 wt.\%) suggests an enhanced interaction between the precursors for BP-Im-Fe sample. Regarding the pyrolyzed materials, the XRD pattern of BPDP-Fe- $\mathrm{NH}_{3}$ (Fig. S3a) showed the presence of iron oxide, $\mathrm{Fe}_{3} \mathrm{O}_{4}$ or $\gamma-\mathrm{Fe}_{2} \mathrm{O}_{3}$, with the most intense peaks at $2 \theta=30,6^{\circ}, 35,5^{\circ}$ and $56^{\circ}$, corresponding to (200), (311), and (511) diffraction plans, respectively [29]. The formation of an iron oxide phase during the pyrolysis in $\mathrm{NH}_{3}$ atmosphere can be ascribed to the high amount of oxygen functional groups on BP and the contribution of the hydroxyl groups in the dopamine. The iron oxide phase might undergo only to a partial reduction due to the carbon matrix microstructure effect, by incorporation of iron oxide in carbon-based nanostructures $[61,62]$ hampering the iron oxide interaction with the reducing gas. This consideration is supported by other studies in which iron oxide phases were also found after heat treatment in $\mathrm{NH}_{3}$ atmosphere $[60,63]$.

The peaks for iron oxide are absent in the diffractogram of all other samples. While metal iron has no activity towards ORR, Fe$\mathrm{N}_{\mathrm{X}}$ and iron oxide can be considered ORR active sites, iron oxide sites having lower catalytic activity as compared to $\mathrm{Fe}-\mathrm{N}_{\mathrm{X}}$ moieties 
(a)

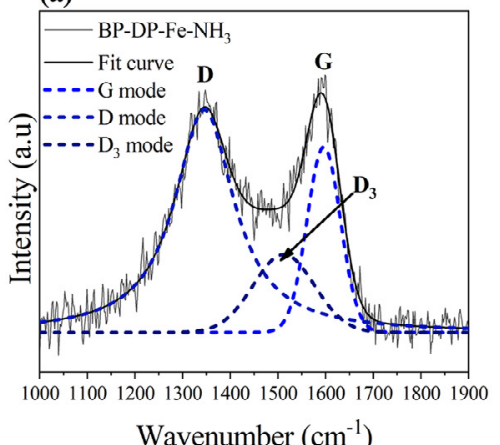

(d)
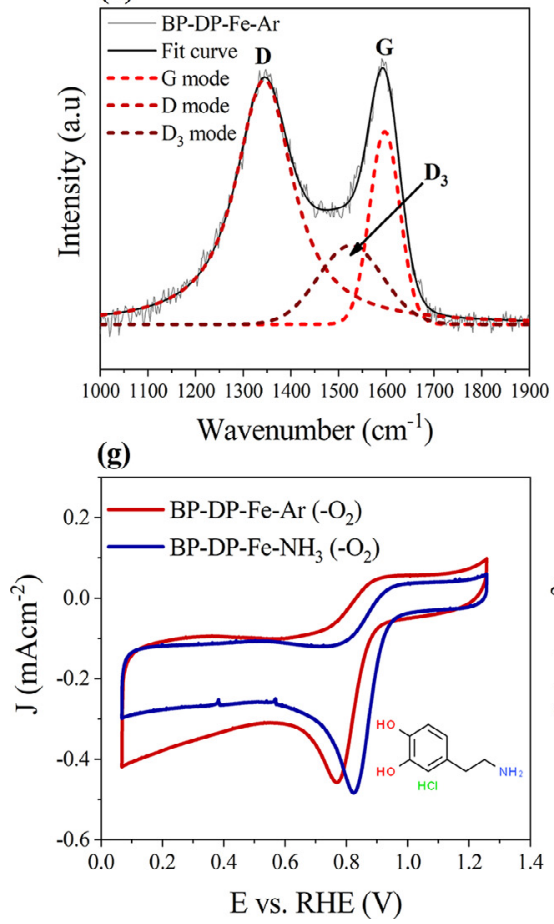

(b)

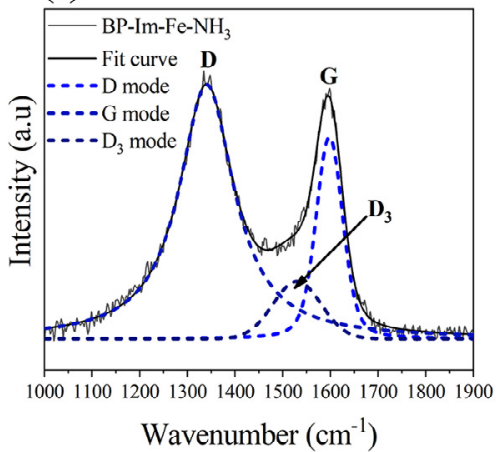

(e)

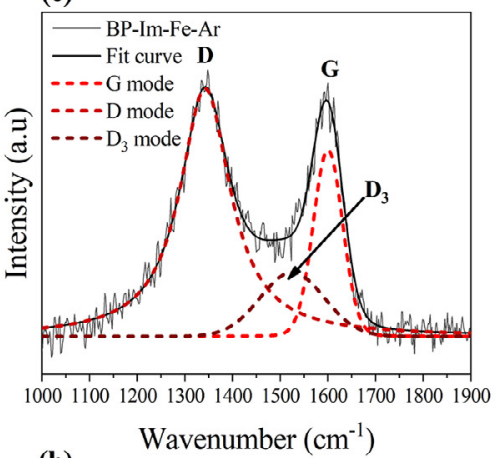

(h)

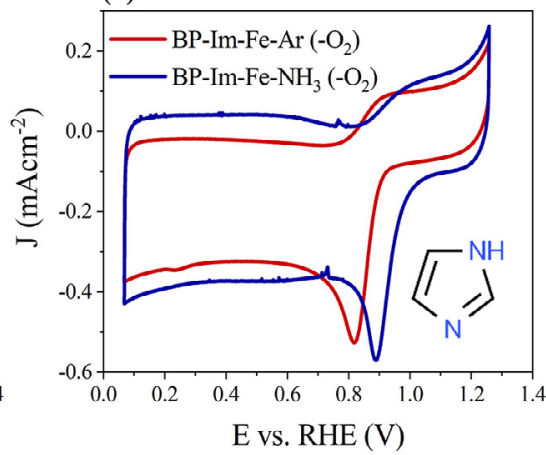

(c)

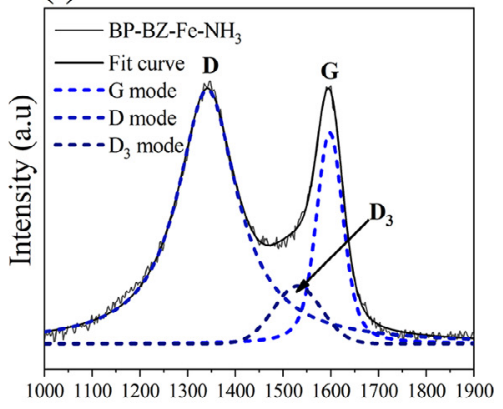

Wavenumber $\left(\mathrm{cm}^{-1}\right)$

(f)

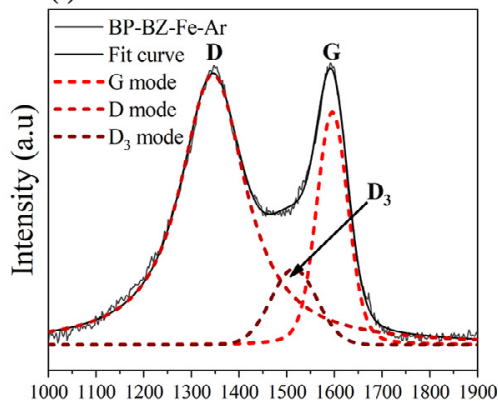

(i) Wavenumber $\left(\mathrm{cm}^{-1}\right)$

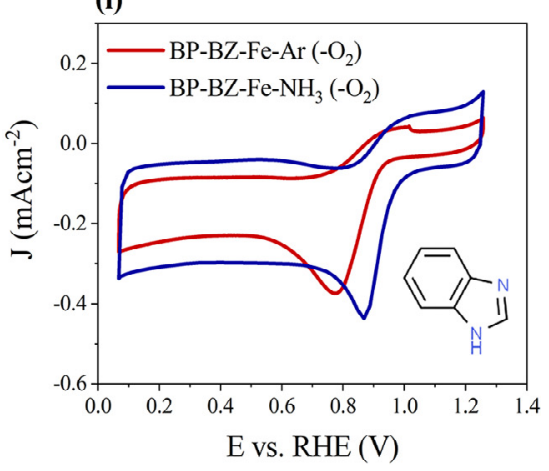

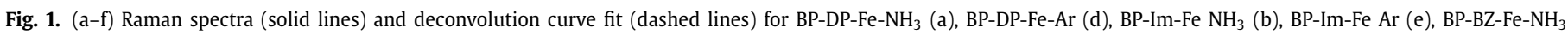

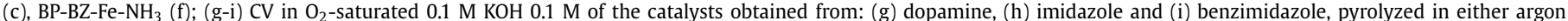
(red) or ammonia (blue) atmosphere (For interpretation of the references to color in this figure legend, the reader is referred to the web version of this article).

[64]. The diffraction patterns of all Fe-N-C catalysts and precursors are shown in Figs. S3 and S4, respectively.

Raman spectra of BP-DP, Fe, BP-Im-Fe, and BP-BZ-Fe before and after the pyrolysis treatment in either $\mathrm{Ar}$ or $\mathrm{NH}_{3}$ are shown in Fig. 1a-f, together with a three-function deconvolution fit for all spectra. All samples show the $G$ band centered at around $1580 \mathrm{~cm}^{-1}$, arising from the $\mathrm{E}_{2 \mathrm{~g}}$ vibrational mode of $\mathrm{sp}^{2}$ domains of graphitic carbon and the $D$ band around $1350 \mathrm{~cm}^{-1}$, a defect induced band arising from $A_{1 g}$ vibrational modes; a shoulder of the $G$ band in between 1500 and $1550 \mathrm{~cm}^{-1}$ (indicated as $D_{3}$ or amorphous-Am band) is also visible in the Raman spectra of all samples and can be ascribed to amorphous $\mathrm{sp}^{2}$ carbon domain arising from the presence of interstitial defects $[43,44]$. The results of deconvolution curve fit of the spectra are summarized in Table S3. The intensity ratio of the $D$ and $G$ bands $\left(\mathrm{I}_{\mathrm{D}} / \mathrm{I}_{\mathrm{G}}\right)$ is indicative of the degree of disorder in the material, thus, it can be also related to the density of functional groups in the carbon framework $[65,66]$. The pyrolysis in ammonia contributed to a slight increase in defects in the structure of BP-Im-Fe and BP-BZ-Fe, while the opposite is true for the catalyst prepared by using dopamine as nitrogen source (BP-DP-Fe). Such observation suggests that this pyrol- ysis atmosphere did not favor the interaction between dopamine and the carbon support. This behavior is in turn related to the analysis by XRD, whose diffractogram of BP-DP-Fe- $\mathrm{NH}_{3}$ indicated the presence of iron oxide, that is indicative of saturation of the $\mathrm{N}_{\mathrm{X}}$-C sites by iron (II) [64]. For the catalysts synthesized from imidazole compounds, it is worth noting that $\mathrm{I}_{\mathrm{D}} / \mathrm{I}_{\mathrm{G}}$ ratio was very similar for BP-Im-Fe-Ar and BP-Im-Fe- $\mathrm{NH}_{3}$, while $\mathrm{I}_{\mathrm{D}} / \mathrm{I}_{\mathrm{G}}$ ratio for BP$\mathrm{BZ}-\mathrm{Fe}-\mathrm{NH}_{3}$ was higher than that of BP-BZ-Fe-Ar. This finding indicates a similar contribution of imidazole to $\mathrm{N}$-functionalization of the carbon matrix in both pyrolysis atmosphere. As far as BP-BZ$\mathrm{Fe}$ is concerned, the pyrolysis in $\mathrm{NH}_{3}$ had a strong contribution in increasing structural defects as compared to pyrolysis in argon.

Cyclic voltammetry (CV) in $\mathrm{N}_{2}$-saturated electrolyte (Fig. S5) was used for calculating the electrochemical active surface area (ECSA) of the Fe-N-C catalysts, which was the range of 200$900 \mathrm{~m}^{2} \mathrm{~g}^{-1}$ (Table S4) in good agreement with previous values found in the literature for other PGM-Free catalysts [67-69]. The catalysts prepared by using imidazole as precursor (BP-Im-Fe-Ar and BP-Im-Fe- $\mathrm{NH}_{3}$ ) had the highest ECSA values as compared to the catalysts prepared by using dopamine and benzimidazole. Moreover, pyrolysis in $\mathrm{NH}_{3}$ allowed increasing ECSA of BP-Im-Fe- 
Table 1

Number of electrons transferred $(\mathrm{n})$ and peroxide percentage $\left(\mathrm{HO}_{2}^{-} \%\right)$ of Fe-N-C catalysts and carbon support at scan rate of 5 mVs ${ }^{-1}$ and rotation speed of $1600 \mathrm{rpm}$ at both half-wave potential and at $0.5 \mathrm{~V}$ vs. RHE (* $0.03 \mathrm{v}$ vs RHE for Pt/C only).

\begin{tabular}{|c|c|c|c|c|c|c|}
\hline \multirow{2}{*}{ Sample } & \multirow{2}{*}{$\begin{array}{l}\text { Half-wave potential }\left(\mathrm{E}_{1 / 2}\right) \\
\text { E vs. RHE (V) }\end{array}$} & \multirow{2}{*}{$\begin{array}{l}J_{\lim } \\
\left(\mathrm{mAcm}^{-2}\right) \text { at } 0.5 \mathrm{~V}\end{array}$} & \multicolumn{2}{|c|}{ Number of electrons transferred (n) } & \multicolumn{2}{|l|}{$\mathrm{HO}_{2}^{-}(\%)$} \\
\hline & & & $\mathrm{E}=\mathrm{E}_{1 / 2}$ & $\mathrm{E} v s . \mathrm{RHE}=0.5 \mathrm{~V}$ & $\mathrm{E}=\mathrm{E}_{1 / 2}$ & $\mathrm{E} v s . \mathrm{RHE}=0.5 \mathrm{~V}$ \\
\hline $\mathrm{BP}$ & 0.78 & -2.39 & $2.29 \pm 0.07$ & $2.34 \pm 0.05$ & $85.6 \pm 3.3$ & $84.1 \pm 2.6$ \\
\hline BP-Im-Fe-Ar & 0.82 & -3.82 & $3.96 \pm 0.01$ & $3.69 \pm 0.01$ & $2.1 \pm 0.3$ & $15.5 \pm 0.2$ \\
\hline BP-Im-Fe-NH ${ }_{3}$ & 0.85 & -4.63 & $3.99 \pm 0.01$ & $3.80 \pm 0.01$ & $0.54 \pm 0.05$ & $9.9 \pm 0.3$ \\
\hline BP-BZ-Fe-Ar & 0.72 & -2.98 & $3.84 \pm 0.01$ & $3.23 \pm 0.04$ & $7.8 \pm 0.6$ & $38.2 \pm 2.2$ \\
\hline BP-BZ-Fe- $\mathrm{NH}_{3}$ & 0.84 & -3.92 & $3.97 \pm 0.01$ & $3.45 \pm 0.03$ & $1.5 \pm 0.6$ & $27.5 \pm 1.3$ \\
\hline $\mathrm{Pt} / \mathrm{C}$ & 0.90 & -5.40 & $3.98 \pm 0.01$ & $3.85 \pm 0.03^{*}$ & $1.40 \pm 0.28$ & $7.5 \pm 0.7^{*}$ \\
\hline
\end{tabular}

$\mathrm{NH}_{3}$ and BP-BZ-Fe- $\mathrm{NH}_{3}$ as compared to the catalysts obtained by pyrolysis in argon. This finding is in good agreement with SEM and Raman analysis indicating the beneficial role of pyrolysis in ammonia in increasing the content of defects and functional groups in the $\mathrm{M}-\mathrm{N}_{\mathrm{x}}-\mathrm{C}$ matrix for the samples prepared by using imidazolic compounds as nitrogen-rich organic precursors. The effect of $\mathrm{NH}_{3}$ gas in enhancing pore formation and $\mathrm{N}_{\mathrm{x}}-\mathrm{C}$ functionalization can be related to possible reactions with imidazole and benzimidazole that favor their interaction with BP used as support. By contrast, ECSA of BP-DP-Fe-NH $\mathrm{NH}_{3}$ was lower than that of BP-DP-Fe-Ar, because of a poor interaction of DP and BP in $\mathrm{NH}_{3}$ atmosphere, as previously pointed out by XRD and Raman results.

CVs were also acquired in $\mathrm{O}_{2}$-saturated $\mathrm{KOH}$ electrolyte to evaluate ORR activity of the prepared materials (Fig. $1 \mathrm{~g}$ and i). A welldefined reduction peak centered at around $0.8 \mathrm{~V}$ can be seen for all samples, indicating a good activity towards ORR. The samples synthesized with imidazole and benzimidazole (BP-Im-Fe and BPBZ-Fe) had more positive peak potential in both pyrolysis conditions than those of BP-DP-Fe, indicating a higher catalytic activity. This can be ascribed to the presence of iron oxide in the samples obtained by using dopamine as precursors, as revealed by XRD analysis. Furthermore, pyrolysis in ammonia improved ORR performance of the catalysts compared with those pyrolyzed in argon, in terms of more positive $E_{p}$ and $J_{\mathrm{p}}$ values (Table S4). As expected, the higher ECSA of the samples pyrolyzed in $\mathrm{NH}_{3}$ together with the higher density of defect and functional groups improve ORR activity.

To get deeper insights into ORR mechanism at the surface of Fe-N-C catalysis, LSV-RRDE experiments were carried out. Given their higher ORR activity as compared to dopamine-based samples, the LSV analyses were limited to the materials prepared by using the imidazolic compound as nitrogen sources. Fig. 2a shows $J_{\text {disk }}$ for BP-Im-Fe- $\mathrm{NH}_{3}$ and BP-BZ-Fe- $-\mathrm{NH}_{3}$ at $1600 \mathrm{rpm}$ electrode rotation rate, together with LSV of bare BP taken as control. From $J_{\text {ring, }}$, the peroxide percentage and the number of electrons exchanged during ORR were calculated and reported in Fig. $2 \mathrm{~b}$ and Table 1. For the sake of comparison, $\mathrm{n}$ values were also calculated by the Koutecky-Levich (K-L) theory [70], acquiring LSVs as a function of the electrode rotation rates (Fig. S6). $n$ values calculated by the K-L theory (Table S5) were in good agreement with $n$ values calculated by RRDE experiments, confirming the reliability of $n$ data.

From $J_{\text {disk, }}$, half-wave potential $\left(\mathrm{E}_{1 / 2}\right)$ and limiting current density $\left(J_{\lim }\right)$ values were extrapolated and listed in Table 1 , together with $E_{1 / 2}, J_{\text {lim }}$ and $n$ values of Pt/C extracted from Fig. S8(b and c) and taken as control. For both series of PGM-free catalysts, $n$ values approach to 4 , indicating a direct $4 \mathrm{e}^{-}$transfer mechanism for Fe-N-C catalysts, as in the case of $\mathrm{Pt} / \mathrm{C}$. On the other hand, $n$ became slightly lower than 4 in the region of higher overpotential due to the contribution of the carbon support at which ORR proceed through an indirect mechanism in $2 \mathrm{e}^{-}$steps [71]. It is well known that ORR at carbonaceous metal-free materials is a $2 \mathrm{e}^{-}$ mechanism with production of peroxide as product of the reduction reaction, the amount of peroxide produced depending on the catalyst loading and porosity [72-74]. Consistently with CV analysis, the materials pyrolyzed in $\mathrm{NH}_{3}$ show more positive values of $\mathrm{E}_{1 / 2}$ and higher $n$, indicating higher catalytic activity; this effect is more pronounced for the sample prepared with benzimidazole as nitrogen-rich precursor. On the other hand, higher $\mathrm{n}$ and $J_{\text {lim }}$ values together with more positive $E_{1 / 2}$ values pointed at a higher catalytic activity of BP-Im-Fe than that of BP-BZ-Fe. This trend was also confirmed by EIS analysis (Fig. S9), indicating that the charge transfer resistance $\left(R_{c t}\right)$ for ORR decreased for the samples pyrolyzed in ammonia, BP-Im-Fe- $\mathrm{NH}_{3}$ showing the lowest $\mathrm{R}_{\mathrm{ct}}$ values (Table S6).

LSV-RRDE experiments were also used to draw Tafel plots, by plotting $i$-corrected potential values as a function of the logarithm of the kinetic current density, and the results are shown in Fig. 2c and $\mathrm{d}$. The plots were linearly fitted in the low current density (lcd) region, from ca 0.9 to $c a 0.85 \mathrm{~V}$ vs. RHE, and in the high current density (hcd) region, from ca $0.80 \mathrm{~V}$ to ca $0.75 \mathrm{~V}$ vs. RHE. From the linear region/s in the Tafel plot, which corresponds to a Tafel behavior, we calculated the exchange current density $\left(J_{0}\right)$ and the cathodic transfer coefficient $\left(\alpha_{\mathrm{c}}\right)$ after determination of the slope $\left(2.303 R T / \alpha_{c} F\right)$ and the intercept $\left(\mathrm{E}^{0}+\left(2.303 R T / \alpha_{\mathrm{c}} F\right) \log \left(J_{0}\right)\right)$ respectively, according to Eq. (5) $[56,57,75]$. The results of the Tafel analysis are reported in Table S7, together with the parameters of Pt/C extrapolated from Fig. S8d and taken as control.

As far as Tafel slopes are concerned, BP-Im-Fe-Ar, BP-Im-Fe$\mathrm{NH}_{3}$, and BP-BZ-Fe-Ar displayed a lcd Tafel slope in the range of 55 to $80 \mathrm{mVdec}^{-1}$ and a hcd Tafel slope in the range of 86 to $160 \mathrm{mVdec}^{-1}$. Those values are similar to the Tafel slopes obtained for Pt/C (Table S7), which are in good agreement with previous works dealing with Pt-based electrodes [57,76].

BP-Im-Fe-Ar displayed a lcd Tafel slope of $55 \mathrm{mVdec}^{-1}$ and a hcd Tafel slope of $86 \mathrm{mVdec}^{-1}$. If the sample is pyrolyzed in $\mathrm{NH}_{3}$ (BP-Im-Fe- $\mathrm{NH}_{3}$ ), the two Tafel slopes are maintained but their value increased. In the case of the samples obtained by using benzimidazole, the pyrolysis in ammonia promotes the shift between two Tafel slopes values for BP-BZ-Fe-Ar and a single Tafel slope for $\mathrm{BP}-\mathrm{BZ}-\mathrm{Fe}-\mathrm{NH}_{3}$. This finding suggests that the rate determining step (rds) of ORR changed with the pyrolysis atmosphere for the catalyst synthesized from benzimidazole, while the same rds mechanism is maintained for the materials obtained from imidazole. Regarding ORR kinetics in alkaline media, Shinagawa and coworkers dealt with an associative mechanism considering $\mathrm{OO}^{-}$anion as an intermediated species. The elementary steps shown in Table 2 are related to the predicted Tafel slope behavior based on the reported study [77]. Based on these theoretical predictions, two different values of Tafel slope in the lcd and hcd regions for BP-Im-Fe-Ar, $\mathrm{BP}-\mathrm{Im}-\mathrm{Fe}-\mathrm{NH}_{3}$, and BP-BZ-Fe-Ar can indicate a $\mathrm{rds}$ characterized by the second electron transfer and splitting of the O-O bond [78] as represented by Eq. (4a) in Table 2. The different values of slopes for BP-Im-Fe-Ar, BP-Im-Fe-NH $\mathrm{NH}_{3}$, particularly in the hcd zone, can be related to a different surface chemistry of the catalysts leading to different extent of hydroxyl anion adsorption $\left(\mathrm{OH}_{\text {ads }}\right)$. This behavior has been previously reported for Pt (100) and Pt (110) in alka- 
(a)

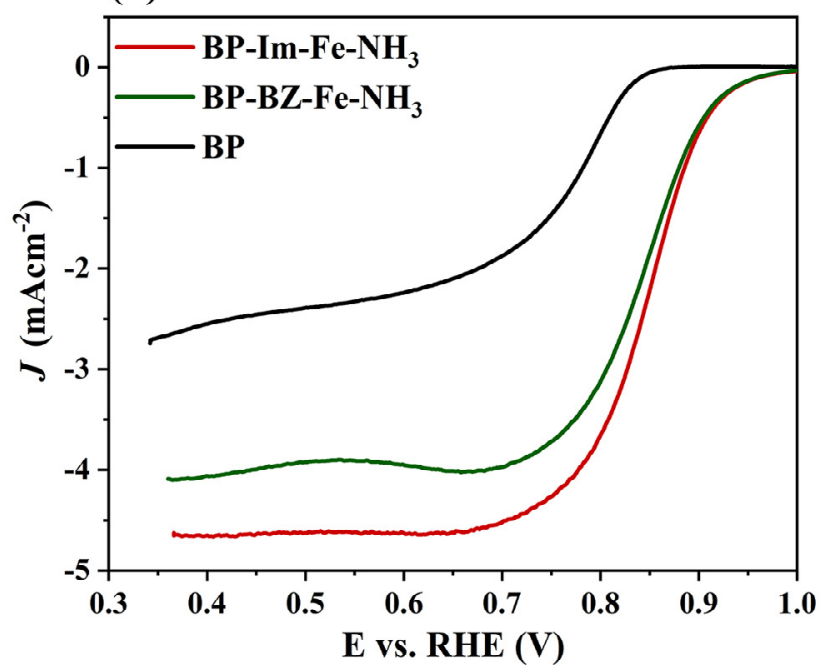

(c)

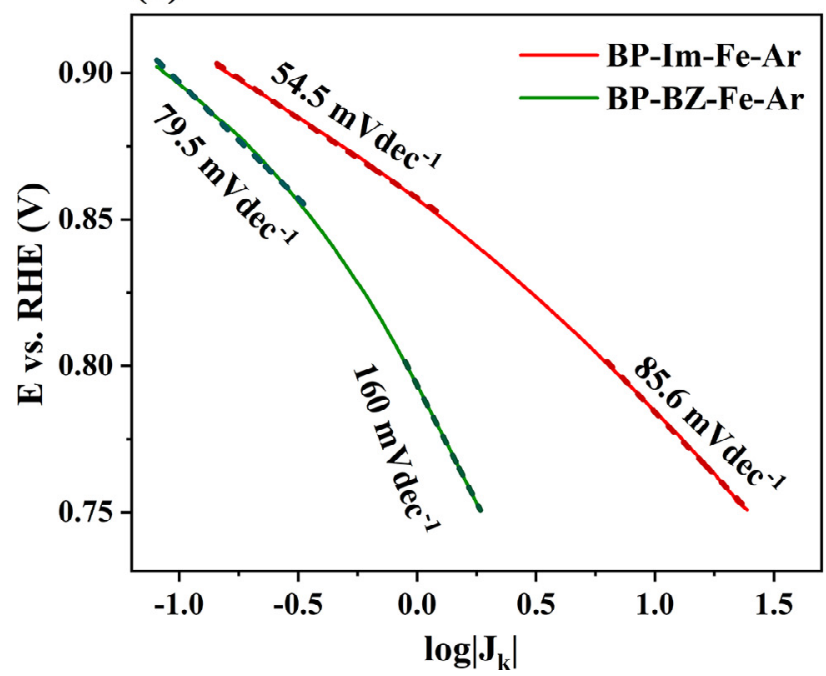

(b)

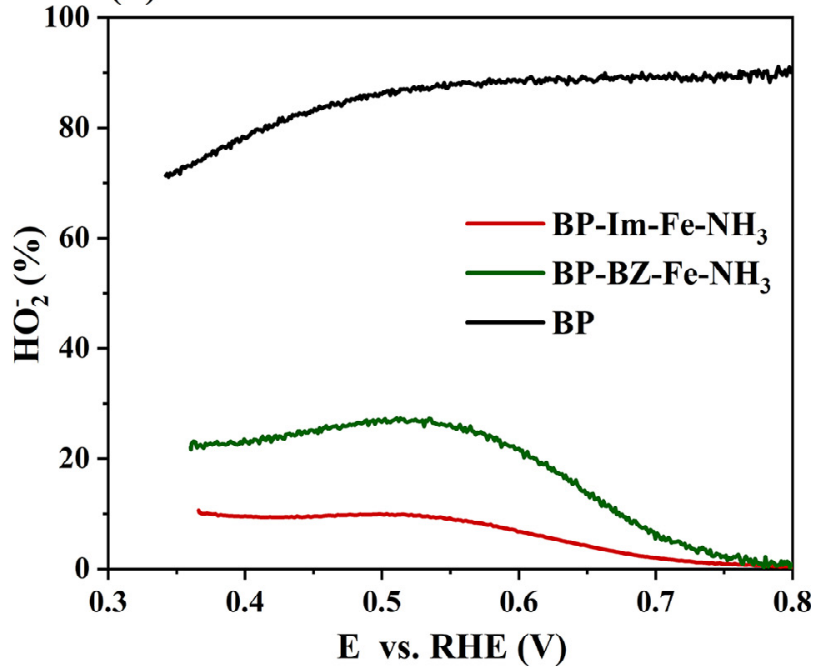

(d)

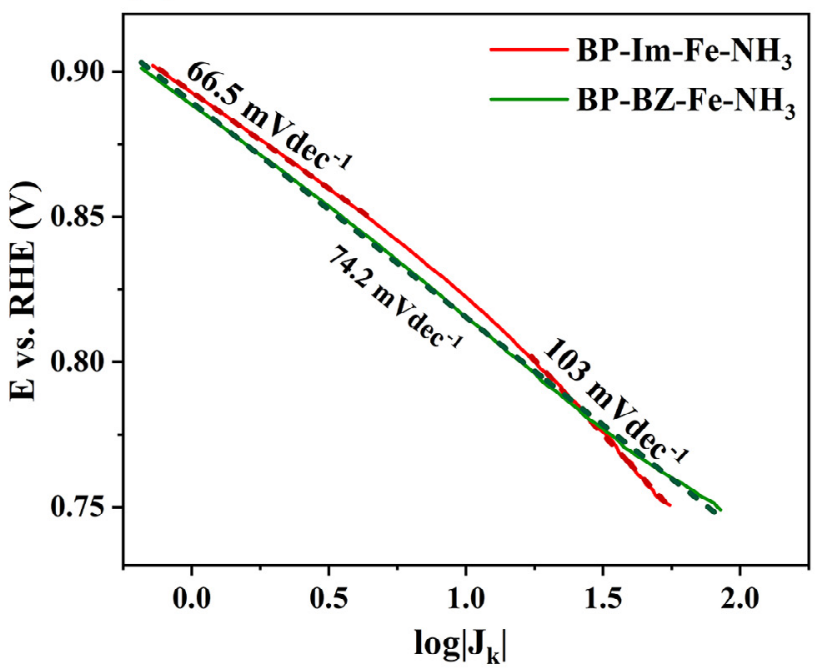

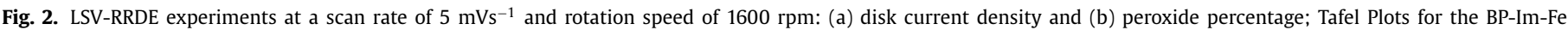
and BP-BZ-Fe pyrolyzed in argon (c) and ammonia atmosphere (d).

Table 2

ORR elementary steps in alkaline Eqs. (1)-(4) and acid Eq. (5), where $M$ denotes an empty active site on the catalysts surface, and predicted Tafel slopes for each considered mechanism.

\begin{tabular}{llll}
\hline Eqs. & Elementary step & $\mathbf{1}^{\text {st }}$ Slope Icd zone & 2 $^{\text {nd }}$ Slope hcd zone \\
\hline 1 & $\mathrm{M}+\mathrm{O}_{2} \rightleftharpoons \mathrm{MO}_{2}$ & - & - \\
2 & $\mathrm{MO}_{2}+\mathrm{e}^{-} \rightleftharpoons \mathrm{MO}_{2}^{-}$ & 120 & - \\
3 & $\mathrm{MO}_{2}^{-}+\mathrm{H}_{2} \mathrm{O} \rightleftharpoons \mathrm{MO}_{2} \mathrm{H}+\mathrm{OH}^{-}$ & 60 & - \\
$4 \mathrm{a}$ & $\mathrm{MO}_{2} \mathrm{H}+\mathrm{e}^{-} \rightleftharpoons \mathrm{MO}+\mathrm{OH}^{-}$or $\mathrm{MO}_{2} \mathrm{H}+\mathrm{e}^{-} \rightleftharpoons \mathrm{MOOH}^{-}$ & 40 & 120 \\
$4 \mathrm{~b}$ & $\mathrm{MO}_{2}^{-}+\mathrm{H}_{3} \mathrm{O}^{+}+\mathrm{e}^{-} \rightleftharpoons \mathrm{MO}_{2} \mathrm{H}+\mathrm{H}_{2} \mathrm{O}$ & 120 & - \\
5 & $\mathrm{M}^{-}$ & & - \\
\hline
\end{tabular}

line environment: among $\mathrm{OH}_{\mathrm{ads}}$, reversible $\left(\mathrm{OH}_{\mathrm{rv}}\right)$ and irreversible $\left(\mathrm{OH}_{\mathrm{ir}}\right)$ forms can be present. $\mathrm{OH}_{\mathrm{rv}}$ species only affects the initial adsorption of $\mathrm{O}_{2}$, while $\mathrm{OH}_{\mathrm{ir}}$ affects both the initial adsorption of $\mathrm{O}_{2}$ and the reaction mechanism conducting to site blocking effect to $\mathrm{O}_{2}$ and higher peroxide production $[79,80]$.

In fact, BP-Im-Fe-Ar (slope $=86 \mathrm{mVdec}^{-1}$ ) show a higher percentage of $\mathrm{HO}_{2}^{-}$intermediate compared to BP-Im-Fe- $\mathrm{NH}_{3}$ (slope $=103 \mathrm{mVdec}^{-1}$ ) suggesting the presence of $\mathrm{OH}_{\mathrm{ir}}$ species over the considered potential range for the sample pyrolyzed in inert atmosphere. As shown in Fig. 3d, BP-BZ-Fe- $\mathrm{NH}_{3}$ shows a unique Tafel slope over the entire potential range suggesting a rds char- acterized by the Eq. (3) in Table 2. According to previous reports dealing with similar PGM-free catalyst, we exclude the first electron transfer as $r d s$ reaction for Fe-N-C catalyst in alkaline environment [78]. The change in ORR $r d s$ promoted by pyrolysis in $\mathrm{NH}_{3}$ for the sample obtained by benzimidazole indicates the contribution of ammonia in modifying BP-BZ-Fe active sites: as pointed out by $\mathrm{CV}, \mathrm{ECSA}$ of $\mathrm{BP}-\mathrm{BZ}-\mathrm{Fe}-\mathrm{NH}_{3}$ were much higher than those of BPBZ-Fe-Ar, while the increase in ECSA after pyrolysis in ammonia was lower for the Im-based sample than in the case of BZ-based samples. The values of $\alpha_{\mathrm{c}}$ for BP-BZ-Fe-Ar, BP-Im-Fe-Ar, and BP$\mathrm{BZ}-\mathrm{Fe}-\mathrm{NH}_{3}$ in the $l c d$ zone are as high as or higher than 0.7 , while 
(a)

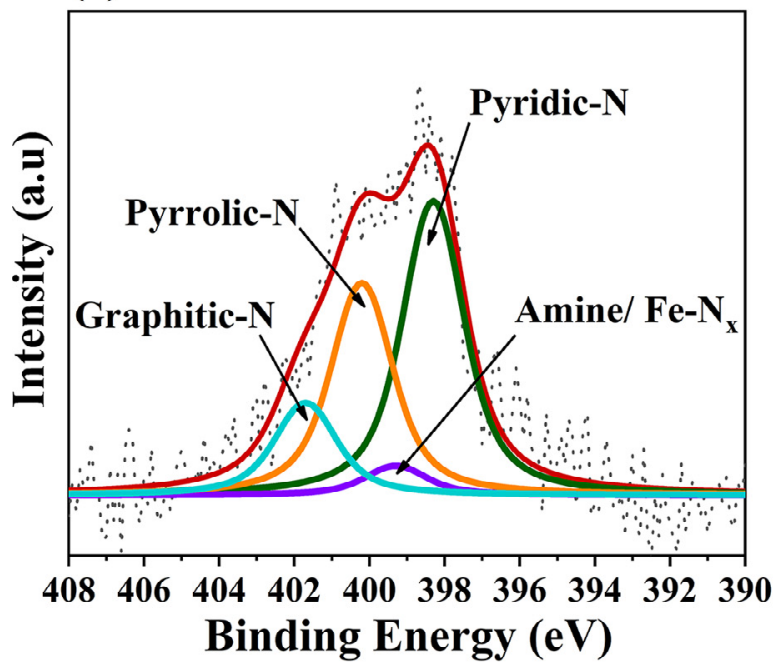

(c)

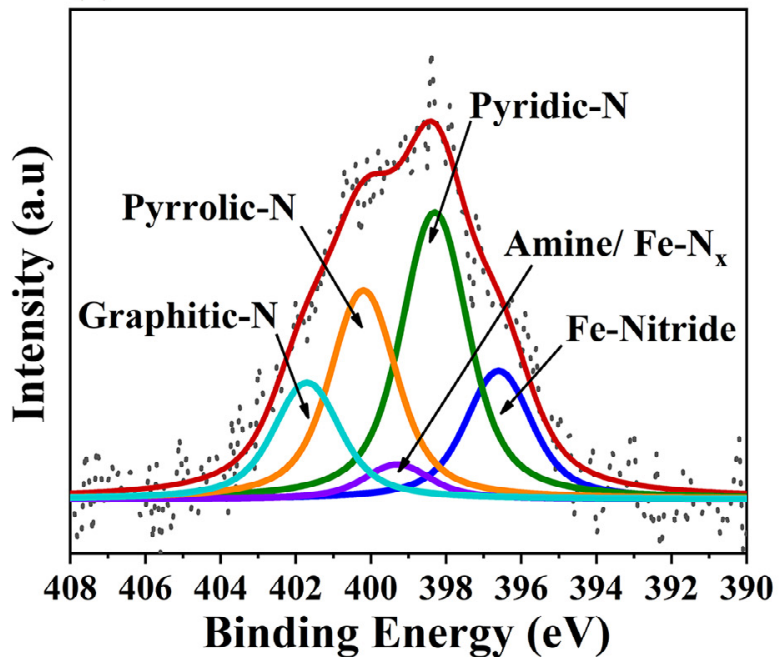

(b)

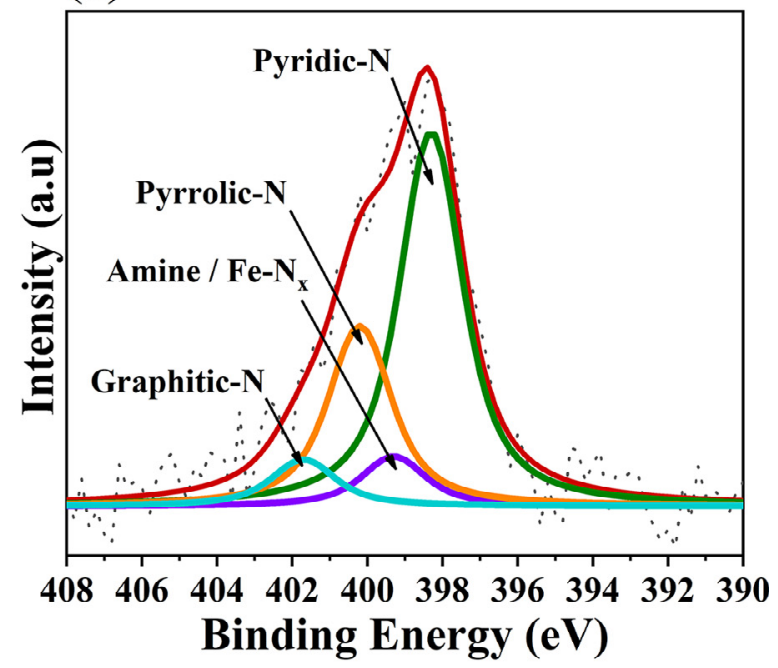

(d)

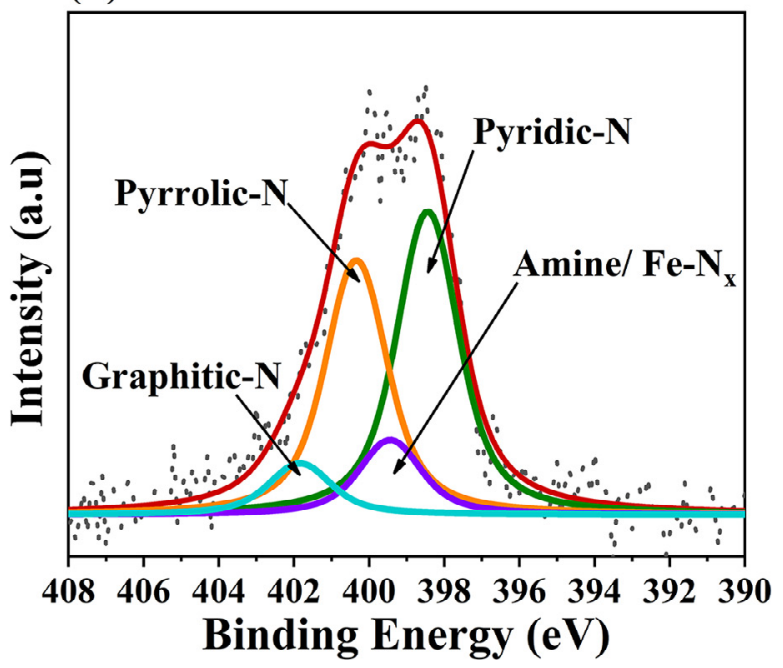

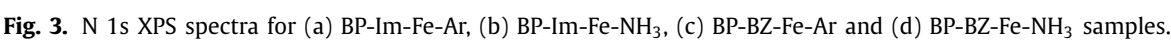

Table 3

Elemental composition and nitrogen atom speciation obtained by XPS analysis.

\begin{tabular}{llllllll}
\hline Sample & C(At. \%) & O(Rel.\%) & N(At. \%) & Graphitic-N (Rel. \%) & Pyrrolic-N (Rel. \%) & Pyridinic-N (Rel. \%) & Amine/Fe-N (Rel. \%) $^{\text {Fe(At. \%) }}$ \\
\hline BP-Im-Fe-Ar & 68.91 & 28.84 & 1.82 & 14.86 & 33.05 & 47.30 & 4.76 \\
BP-Im-Fe-NH 3 & 70.74 & 27.24 & 1.90 & 7.17 & 27.67 & 57.52 & 7.64 \\
BP-BZ-Fe-Ar & 67.16 & 28.61 & 3.77 & 15.05 & 26.92 & 37.01 & 0.12 \\
BP-BZ-Fe-NH & 68.94 & 28.29 & 2.72 & 7.52 & 37.20 & 44.35 & 0.46 \\
\hline
\end{tabular}

they decreased in the hcd zone, because of their dependence on overpotential that favors the reduction reaction kinetics.[81,82] In the hcd zone, they ranged from 0.4 to 0.7 , which can be approximated to the behavior for the symmetry of the barrier reaction, in which $\alpha_{\mathrm{c}}$ is 0.5 , that shows a typical Tafel slope of $118 \mathrm{mVdec}^{-1}$, according to Tafel analysis from the Butler-Volmer model [81]. Exchange current density values of our Fe-based catalysts are similar to $J_{0}$ values of $\mathrm{Pt} / \mathrm{C}$ and in good agreement with previously reported $J_{0}$ values of platinum-based and other PGM-Free catalysts in alkaline media [76,83]. An increase in $J_{0}$ was observed for the sample pyrolyzed in $\mathrm{NH}_{3}$, as a further confirm of beneficial effect of ammonia in enhancing catalytic activity for ORR due to surface chemistry modification of the catalysts as suggested by Tafel analysis.
Surface stoichiometry of the catalysts was investigated by XPS and Fig. 3 shows XPS spectra of $\mathrm{N} 1 \mathrm{~s}$ for the Fe-N-C catalysts obtained from imidazole and benzimidazole. Elemental analysis estimated from the C $1 \mathrm{~s}, \mathrm{~N} 1 \mathrm{~s}$ and Fe2p spectra is reported in Table 3. Chemical speciation of carbon and nitrogen atoms, obtained by the deconvolution of C 1 s (Fig. S10) and N 1 s spectra, is reported in Tables S8 and S9. The sample composition mainly consists of carbon and oxygen, with a lower content of nitrogen and iron. Iron content was higher for both catalysts pyrolyzed in argon, indicating a beneficial effect of the inert atmosphere for iron retention in the carbon matrix. On the other hand, the analysis of $\mathrm{N} 1 \mathrm{~s}$ spectra indicates that pyrolysis in ammonia lead to an increase of the relative content of amine/Fe- $\mathrm{N}_{\mathrm{X}}$ species (which behave as ORR active sites) for both samples, and the disappearance of iron ni- 
(a)

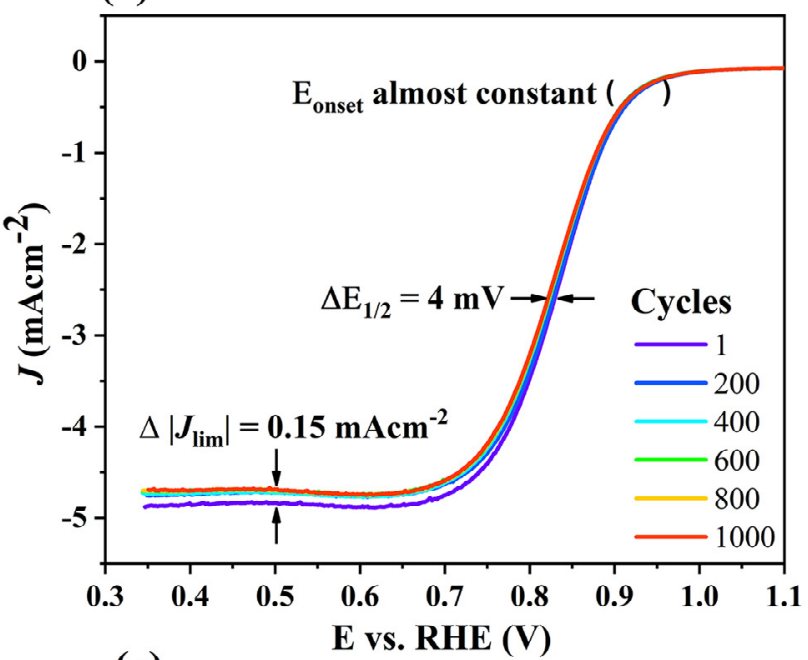

(c)

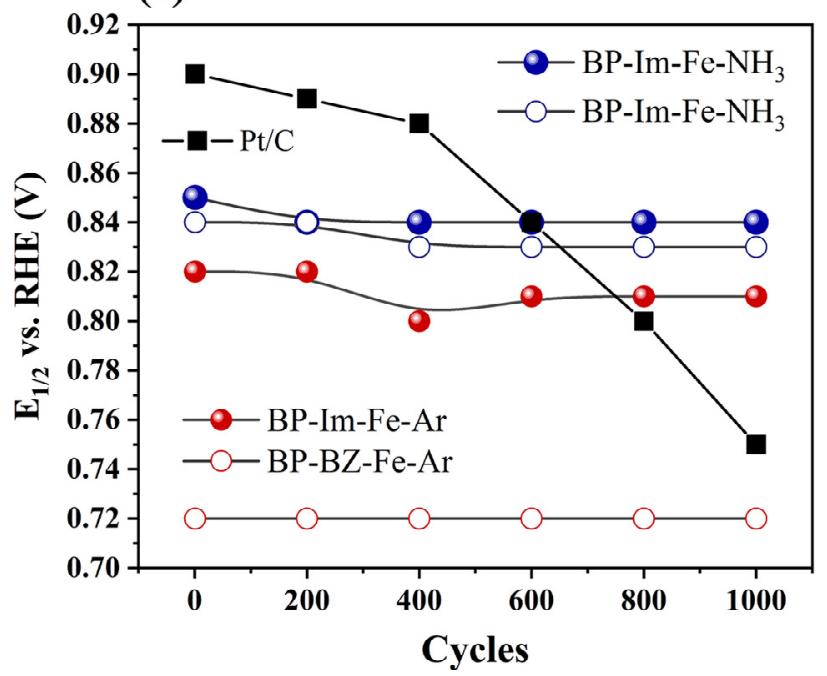

(b)

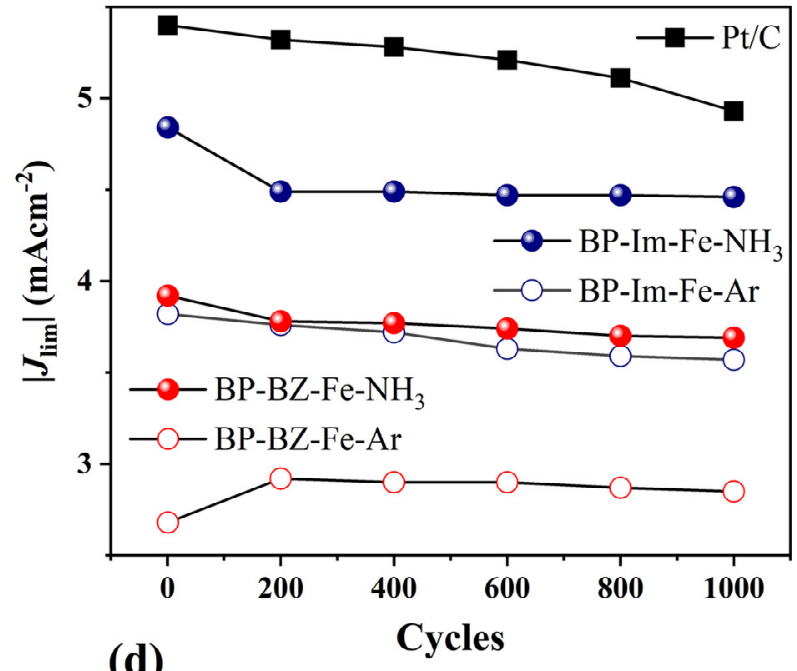

(d)

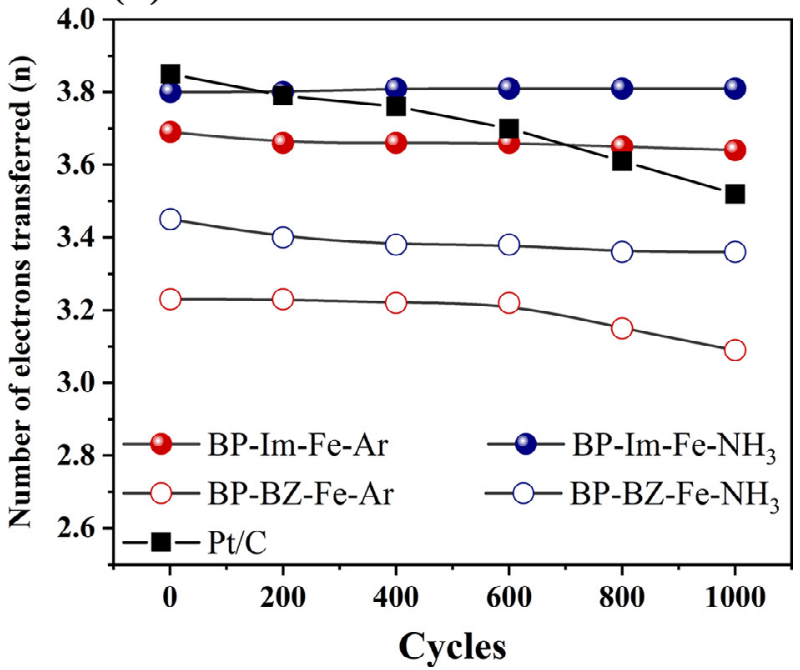

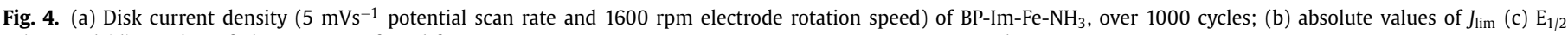
values and (d) number of electrons transferred for BP-Im-Fe-NH 3 , BP-Im-Fe-Ar, BP-BZ-Fe-NH, BP-BZ-Fe-Ar and PtC.

tride species (inactive ORR sites) [84,85] for BP-BZ-Fe sample, thus explaining the higher catalytic activity of the samples pyrolyzed in ammonia. The analysis of C $1 \mathrm{~s}$ spectra for all materials (Table S8) indicated the functionalization of the carbon support with oxygen and nitrogen containing groups. As far as N1 s spectra are concerned, all samples showed the presence of pyridinic, pyrrolic, graphitic nitrogen, and amine/Fe- $\mathrm{N}_{\mathrm{x}}$ species (Table 3) as typical nitrogen groups in PGM-free catalysts [18,26,86-88]. For both BP-Im$\mathrm{Fe}$ and BP-BZ-Fe, graphitic-N content decreased, and pyridinic-N content increased after pyrolysis in $\mathrm{NH}_{3}$. In the case of BP-Im-Fe, pyrolysis in $\mathrm{NH}_{3}$ lead to a decrease in pyrrolic-N while an opposite trend can be seen for BP-BZ-Fe. The use of a different N-rich organic precursor and pyrolysis atmosphere lead to a different surface stoichiometry, which affects ORR mechanism. A higher content of pyrrolic-N for BP-Im-Fe-Ar as compared to BP-Im-Fe- $\mathrm{NH}_{3}$ leading to a higher capability of adsorbing hydroxyl ions for BPIm-Fe-Ar. Pyrrolic $\mathrm{N}$ tends to accumulate negative charge making the neighboring $C$ atom more electropositive, which causes a decreased energy adsorption of $\mathrm{OH}$ groups, as previously reported $[89,90]$. This finding explains the results obtained in the Tafel analysis, indicating the second electron transfer and splitting of the $\mathrm{O}$ $\mathrm{O}$ bond as rds mechanism for ORR at the surface of both BP-Im-Fe$\mathrm{Ar}$ and BP-Im-Fe- $\mathrm{NH}_{3}$, with a lower Tafel slope in the hcd zone for
BP-Im-Fe-Ar due to the higher content of pyrrolic nitrogen. By contrast, the electron donor character of amine [91], in higher percentage in BP-BZ-Fe- $\mathrm{NH}_{3}$ compared to BP-BZ-Fe-Ar, possibly favored $\mathrm{O}_{2}$ adsorption leading to the formation of $\mathrm{MO}_{2}{ }^{-}$species, where $\mathrm{M}$ denotes an active catalytic site, and promoting the $r d s$ mechanism represented in Eq. (3) (Table 2).

In addition to the activity, durability was also investigated since it is a key parameter for high-performance electrocatalysts. The start/stop cycle durability tests were performed by acquiring cyclic voltammograms in $\mathrm{N}_{2}$-saturated electrolyte (Fig. S11) to evaluate the ECSA retention over 7000 cycles (Fig. S12a). ECSA for BP-BZ$\mathrm{Fe}-\mathrm{Ar}$ and $\mathrm{BP}-\mathrm{BZ}-\mathrm{Fe}-\mathrm{NH}_{3}$ samples was stable over 7000 cycle with only a $2 \%$ ECSA decrease for BP-BZ-Fe- $\mathrm{NH}_{3}$ sample. Both catalysts synthesized from imidazole, BP-Im-Fe-Ar and BP-Im-Fe- $\mathrm{NH}_{3}$, shown a similar trend, with an initial increase in ECSA during the first 1000 cycles followed by ECSA stabilization over 7000 cycles. The stable behavior of Fe-N-C catalysts in terms of ECSA change during $\mathrm{CV}$ cycles outperformed $\mathrm{Pt} / \mathrm{C}$ taken as control, that experienced a 60\% ECSA loss over the first 1000 cycles (Fig. S12b), in good agreement with previous reports [92].

Stability of catalysts was also assessed evaluating the change in ORR activity after cycling in $\mathrm{O}_{2}$-saturated $0.1 \mathrm{M} \mathrm{KOH}$ (Fig. 4). Fig. 4a shows LSVs over 1000 cycles for BP-Im-Fe- $\mathrm{NH}_{3}$ as a rep- 
resentative sample for the series. All PGM-free catalysts exhibited only a slight decrease (3-7\%) in $J_{\lim }$ during cycling (Fig. $4 \mathrm{~b}$ ), indicating good stability. By contrast, $J_{\lim }$ values for $\mathrm{Pt} / \mathrm{C}$ declined over cycles of about $10 \%$. For PGM-free catalysts, half-wave potential and the number of electrons transferred during ORR were almost stable over 1000 cycles, as indicated by Fig. 4c and 4d, while $E_{1 / 2}$ and $n$ decrease in the region of $17 \%$ and $9 \%$, respectively, for $\mathrm{Pt} / \mathrm{C}$. The variation of all electrochemical parameters ( $E_{\text {onset }}, E_{1 / 2}$ and $J_{\text {lim }}, n$ and $\mathrm{HO}_{2}^{-}$percentage) over cycling was reported in Table S10 for the sake of completeness.

The body of results pointed at high ORR activity in alkaline $\mathrm{pH}$ for BP-Im-Fe-Ar, BP-Im-Fe-NH $\mathrm{N}_{3}$ and BP-BZ-Fe-NH $\mathrm{N}_{3}$ samples, that outperform platinum-based electrocatalysts in terms of durability. Among the three samples, BP-Im-Fe- $\mathrm{NH}_{3}$ demonstrated the most competitive catalytic performance, since it combines the highest ECSA, the most positive $E_{\text {onset }}$ and $E_{1 / 2}$, n closest to 4, with high durability over cycling. BP-Im- $\mathrm{Fe}-\mathrm{NH}_{3}$ performance was comparable or even higher in relation to others $\mathrm{Fe}-\mathrm{N}-\mathrm{C}$ catalysts synthesized with higher iron content characterized in similar conditions $[32,93,94]$.

\section{Conclusion}

Fe-N-C catalysts were synthesized from a wet impregnation of black pearls with nitrogen-rich organic precursors and an iron salt followed by pyrolysis steps. Three different nitrogen sources (dopamine, imidazole and benzimidazole), and two different pyrolysis atmospheres $\left(\mathrm{Ar}\right.$ and $\mathrm{NH}_{3}$ ) were used. Contrary to imidazole and benzimidazole, the use of dopamine as nitrogen-rich organic precursor promotes the presence of iron oxide as active site for ORR with lower catalytic activity as compared to Fe- $\mathrm{N}_{\mathrm{x}}$ active sites. Pyrolysis in $\mathrm{NH}_{3}$ lead to an increase in structural defects and ECSA for the samples obtained with imidazole (Im) and benzimidazole (BZ), as indicated by Raman analysis and CV. This leads to a higher ORR activity than that of Im- and BZ-based samples pyrolyzed in argon. ORR at the surface of BP-Im-Fe and BP-BZ-Fe was found to proceed through a direct $4 \mathrm{e}^{-}$mechanism, as indicated by LSV-RRDE experiments.

Tafel analysis revealed that the rds for ORR at BP-Im-Fe-Ar, BPIm-Fe- $\mathrm{NH}_{3}$, and BP-BZ-Ar is characterized by the second electron transfer that involves consumption of $\mathrm{MOOH}$ species from a high coverage of $\mathrm{MO}_{2}{ }^{-}$. By contrast, the $r d s$ for ORR at BP-BZ-Fe- $\mathrm{NH}_{3}$ sample shifts from an electron transfer step to a coverage step with $\mathrm{MO}_{2}{ }^{-}$species interacting with water molecules. This can be ascribed to the modification of surface chemistry of the electrocatalysts triggered by the $\mathrm{N}$-rich organic precursor and pyrolysis atmosphere, as pointed out by XPS. Pyrrolic-N led to a higher interaction with hydroxide ions, lowering the slopes from the same rds mechanism in the hcd zone, while amine groups promote a $r d s$ mechanism dependent of the coverage of $\mathrm{MO}_{2}^{-}$species. Among the prepared samples, BP-Im-Fe- $\mathrm{NH}_{3}$ demonstrated the most competitive catalytic performance, since it combines the highest ECSA, the most positive $\mathrm{E}_{\text {onset }}$ and $\mathrm{E}_{1 / 2}$, $\mathrm{n}$ closest to 4 , outperforming Ptbased materials in terms of durability during RRDE cycling in durability tests carried out in alkaline environment.

\section{Declaration of Competing Interest}

The authors declare that they have no known competing financial interests or personal relationships that could have appeared to influence the work reported in this paper.

The authors declare the following financial interests/personal relationships which may be considered as potential competing interests:

\section{Credit authorship contribution statement}

Williane da Silva Freitas: Methodology, Investigation, Data curation, Visualization, Writing - original draft. Alessandra D’Epifanio: Conceptualization, Resources, Writing - review \& editing, Funding acquisition. Valerio C.A. Ficca: Methodology, Investigation. Ernesto Placidi: Methodology, Investigation, Resources, Writing - review \& editing. Fabrizio Arciprete: Methodology, Investigation, Resources, Writing - review \& editing. Barbara Mecheri: Conceptualization, Resources, Writing - review \& editing, Supervision, Project administration.

\section{Acknowledgments}

The Regione Lazio is greatly acknowledged for funding the research through the project POR FESR LAZIO 2014-2020, N A03752020-36492. Also, the authors are grateful to the University of Roma Tor Vergata for the Grant "BEYOND BORDERS 2019", Project Name: AEROBIC). The authors acknowledge Mrs. C. D'Ottavi (Dept. Chemical Science and Technologies of the University of Rome Tor Vergata) for her valuable technical support.

\section{Supplementary materials}

Supplementary data associated with this article can be found, in the online version, at doi:10.1016/j.electacta.2021.138899.

\section{References}

[1] I. Staffell, D. Scamman, A. Velazquez Abad, P. Balcombe, P.E. Dodds, P. Ekins, N. Shah, K.R. Ward, The role of hydrogen and fuel cells in the global energy system, Energy Environ. Sci. 12 (2) (2019) 463-491.

[2] H.N. Abdelhamid, A review on hydrogen generation from the hydrolysis of sodium borohydride, Int. J. Hydrog. Energy 46 (1) (2021) 726-765.

[3] A.V Churikov, K.V Zapsis, V.V Khramkov, M.A. Churikov, M.P. Smotrov, I.A. Kazarinov, Density calculations for $\left(\mathrm{Na}, \mathrm{K}^{\circ} \mathrm{BH}_{4}+(\mathrm{Na}, \mathrm{K}) \mathrm{BO}_{2}+(\mathrm{Na}\right.$, $\mathrm{K}) \mathrm{OH}+\mathrm{H}_{2} \mathrm{O}$ solutions used in hydrogen power engineering, J. Chem. Eng. Data 56 (2011) 9-13.

[4] A.V. Churikov, A.V. Ivanishchev, I.M. Gamayunova, A.V. Ushakov, Density calculations for $\left(\mathrm{Na}, \mathrm{K} \mathrm{BH}_{4}+(\mathrm{Na}, \mathrm{K}) \mathrm{BO}_{2}+(\mathrm{Na}, \mathrm{K}) \mathrm{OH}+\mathrm{H}_{2} \mathrm{O}\right.$ solutions used in hydrogen power engineering, J. Chem. Eng. Data 56 (11) (2011) 3984-3993.

[5] A.V. Churikov, I.M. Gamayunova, K.V. Zapsis, M.A. Churikov, A.V. Ivanishchev, Influence of temperature and alkalinity on the hydrolysis rate of borohydride ions in aqueous solution, Int. J. Hydrog. Energy 37 (1) (2012) 335-344.

[6] T.Y. Son, T.H. Ko, V. Vijayakumar, K. Kim, S.Y Nam, Anion exchange composite membranes composed of poly(phenylene oxide) containing quaternary ammonium and polyethylene support for alkaline anion exchange membrane fuel cell applications, Solid State Ion. 344 (2020) 115153 October 2019.

[7] J. Cheng, G. He, F. Zhang, A mini-review on anion exchange membranes for fuel cell applications: stability issue and addressing strategies, Int. J. Hydrog. Energy 40 (23) (2015) 7348-7360.

[8] X. Tan, S. Prabhudev, A. Kohandehghan, D. Karpuzov, G.A. Botton, D. Mitlin, Pt-Au-Co alloy electrocatalysts demonstrating enhanced activity and durability toward the oxygen reduction reaction, ACS Catal. 5 (3) (2015) 1513-1524.

[9] C.H. Choi, M. Kim, H.C. Kwon, S.J. Cho, S. Yun, H.T. Kim, K.J.J. Mayrhofer H. Kim, M. Choi, Tuning selectivity of electrochemical reactions by atomically dispersed platinum catalyst, Nat. Commun. 7 (Iek 11) (2016) 1-9.

[10] X.L. Tian, Y.Y. Xu, W. Zhang, T. Wu, B.Y. Xia, X. Wang, Unsupported platinum-based electrocatalysts for oxygen reduction reaction, ACS Energy Lett. 2 (9) (2017) 2035-2043.

[11] G. Wu, K.L. More, C.M. Johnston, and P. Zelenay (2011) High-performance electrocatalysts for oxygen reduction derived from polyaniline, iron, and cobalt. Science (80)., 332 (6028), 443-447.

[12] M.M. Hossen, K. Artyushkova, P. Atanassov, A. Serov, Synthesis and characterization of high performing $\mathrm{Fe}-\mathrm{N}-\mathrm{C}$ catalyst for oxygen reduction reaction (ORR) in alkaline exchange membrane fuel cells, J. Power Sources 375 (2018) 214-221.

[13] A. Serov, K. Artyushkova, P. Atanassov, Fe-N-C oxygen reduction fuel cell catalyst derived from carbendazim: synthesis, structure, and reactivity, Adv. Energy Mater. 4 (10) (2014) 1-7.

[14] A. Serov, K. Artyushkova, N.I. Andersen, S. Stariha, P. Atanassov, Original mechanochemical synthesis of non-platinum group metals oxygen reduction reaction catalysts assisted by sacrificial support method, Electrochim. Acta 179 (2015) 154-160.

[15] A. Serov, K. Artyushkova, E. Niangar, C. Wang, N. Dale, F. Jaouen, M.T. Sougrati, Q. Jia, S. Mukerjee, P. Atanassov, Nano-structured non-platinum catalysts for automotive fuel cell application, Nano Energy 16 (2015) 293-300. 
[16] E. Negro, A.H.A.M. Videla, V. Baglio, A.S. Aricò, S. Specchia, G.J.M. Koper, Fe-N supported on graphitic carbon nano-networks grown from cobalt as oxygen reduction catalysts for low-temperature fuel cells, Appl. Catal. B Environ. 166-167 (2015) 75-83.

[17] Y. Li, X. Liu, L. Zheng, J. Shang, X. Wan, R. Hu, X. Guo, S. Hong, J. Shui, Preparation of Fe-N-C catalysts with FeNx $(x=1,3,4)$ active sites and comparison of their activities for the oxygen reduction reaction and performances in proton exchange membrane fuel cells, J. Mater. Chem. A 7 (45) (2019) 26147-26153.

[18] Q. Jia, N. Ramaswamy, U. Tylus, K. Strickland, J. Li, A. Serov, K. Artyushkova, P. Atanassov, J. Anibal, C. Gumeci, S.C. Barton, M.T. Sougrati, F. Jaouen, B. Halevi, S. Mukerjee, Spectroscopic insights into the nature of active sites in iron-nitrogen-carbon electrocatalysts for oxygen reduction in acid, Nano Energy 29 (2016) 65-82

[19] Q. Jia, N. Ramaswamy, H. Hafiz, U. Tylus, K. Strickland, G. Wu, B. Barbiellini, A. Bansil, E.F. Holby, P. Zelenay, S. Mukerjee, Experimental observation of redox-induced Fe-N switching behavior as a determinant role for oxygen reduction activity, ACS Nano 9 (12) (2015) 12496-12505.

[20] S. Kabir, K. Artyushkova, A. Serov, B. Kiefer, P. Atanassov, Binding energy shifts for nitrogen-containing graphene-based electrocatalysts-experiments and DFT calculations, Surf. Interface Anal. 48 (5) (2016) 293-300.

[21] L. Lai, J.R. Potts, D. Zhan, L. Wang, C.K. Poh, C. Tang, H. Gong, Z. Shen, J. Lin, R.S. Ruoff, Exploration of the active center structure of nitrogen-doped graphene-based catalysts for oxygen reduction reaction, Energy Environ. Sci. 5 (7) (2012) 7936-7942

[22] J. Li, S. Ghoshal, W. Liang, M.T. Sougrati, F. Jaouen, B. Halevi, S. McKinney, G. McCool, C. Ma, X. Yuan, Z.F. Ma, S. Mukerjee, Q. Jia, Structural and mechanistic basis for the high activity of Fe-N-C catalysts toward oxygen reduction, Energy Environ. Sci. 9 (7) (2016) 2418-2432.

[23] F. Jaouen, M. Lefèvre, J.P. Dodelet, M. Cai, Heat-treated Fe/N/C catalysts for $\mathrm{O}_{2}$ electroreduction: are active sites hosted in micropores? J. Phys. Chem. B 110 (11) (2006) 5553-5558.

[24] E. Proietti, F. Jaouen, M. Lefèvre, N. Larouche, J. Tian, J. Herranz, J.P. Dodelet, Iron-based cathode catalyst with enhanced power density in polymer electrolyte membrane fuel cells, Nat. Commun. 2 (1) (2011).

[25] C. Alegre, D. Sebastián, M.E. Gálvez, E. Baquedano, R. Moliner, A.S. Aricò, V. Baglio, M.J. Lázaro, N-doped carbon xerogels as Pt support for the electro-Reduction of oxygen, Materials 10 (9) (2017) 11-13 (Basel).

[26] B. Mecheri, V.C.A. Ficca, M.A. Costa de Oliveira, A. D’Epifanio, E. Placidi, F. Arciprete, S. Licoccia, Facile synthesis of graphene-phthalocyanine composites as oxygen reduction electrocatalysts in microbial fuel cells, Appl. Catal. B Environ. 237 (2018) 699-707 (June).

[27] M.A. Costa de Oliveira, B. Mecheri, A. D’Epifanio, E. Placidi, F. Arciprete, F. Valentini, A. Perandini, V. Valentini, S. Licoccia, Graphene oxide nanoplatforms to enhance catalytic performance of iron phthalocyanine for oxygen reduction reaction in bioelectrochemical systems, J. Power Sources 356 (2017) 381-388.

[28] F. Jaouen, E. Proietti, M. Lefèvre, R. Chenitz, J.P. Dodelet, G. Wu, H.T. Chung, C.M. Johnston, P. Zelenay, Recent advances in non-precious metal catalysis for oxygen-reduction reaction in polymer electrolyte fuel cells, Energy Environ. Sci. 4 (1) (2011) 114-130.

[29] C. Santoro, R. Gokhale, B. Mecheri, A. D’Epifanio, S. Licoccia, A. Serov, K. Artyushkova, P. Atanassov, Design of iron(II) phthalocyanine-derived oxygen reduction electrocatalysts for high-power-density microbial fuel cells, ChemSusChem 10 (16) (2017) 3243-3251.

[30] P. Du, X. Xiao, F. Ma, H. Wang, J. Shen, F. Lyu, Y. Chen, J. Lu, Y. Li, Fe,N Co-doped mesoporous carbon nanosheets for oxygen reduction, ACS Appl. Nano Mater. 3 (6) (2020) 5637-5644.

[31] Y. Wang, S. Wang, R. Li, H. Li, Z. Guo, B. Chen, R. Li, Q. Yao, X. Zhang, H. Chen, Y. Li, K. Qu, Y. Zheng, A simple strategy for tridoped porous carbon nanosheet as superior electrocatalyst for bifunctional oxygen reduction and hydrogen evolution reactions, Carbon 162 (2020) 586-594 N. Y..

[32] I. Martinaiou, T. Wolker, A. Shahraei, G.R. Zhang, A. Janßen, S. Wagner, N. Weidler, R.W. Stark, B.J.M. Etzold, U.I. Kramm, Improved electrochemical performance of Fe-N-C catalysts through ionic liquid modification in alkaline media, J. Power Sources 375 (2018) 222-232.

[33] E.S.F. Cardoso, G.V. Fortunato, I. Palm, E. Kibena-Põldsepp, A.S. Greco, J.L.R. Júnior, A. Kikas, M. Merisalu, V. Kisand, V. Sammelselg, K. Tammeveski, $G$. Maia, Effects of $N$ and $O$ groups for oxygen reduction reaction on one- and two-dimensional carbonaceous materials, Electrochim. Acta (2020) 344

[34] J. Quílez-Bermejo, E. Morallón, D. Cazorla-Amorós, Metal-free heteroatomdoped carbon-based catalysts for ORR. A critical assessment about the role of heteroatoms, Carbon 165 (2020) 434-454 N. Y..

[35] D.R. Dekel, Review of cell performance in anion exchange membrane fuel cells, J. Power Sources 375 (2018) 158-169.

[36] R. Gokhale, Y. Chen, A. Serov, K. Artyushkova, P. Atanassov, Direct synthesis of platinum group metal-free $\mathrm{Fe}-\mathrm{N}-\mathrm{C}$ catalyst for oxygen reduction reaction in alkaline media, Electrochem. Commun. 72 (2016) 140-143.

[37] M.A. Costa de Oliveira, V.C.A. Ficca, R. Gokhale, C. Santoro, B. Mecheri, A. D’Epifanio, S. Licoccia, P. Atanassov, Iron(II) phthalocyanine (FePc) over carbon support for oxygen reduction reaction electrocatalysts operating in alkaline electrolyte, J. Solid State Electrochem. 25 (2021) 93-104.

[38] X. Peng, T.J. Omasta, E. Magliocca, L. Wang, J.R. Varcoe, W.E. Mustain, Nitrogendoped carbon- $\mathrm{COO}_{\mathrm{x}}$ nanohybrids: a precious metal free cathode that exceeds $1.0 \mathrm{~W} \mathrm{~cm}-2$ peak power and $100 \mathrm{~h}$ life in anion-exchange membrane fuel cells, Angew. Chem. 131 (4) (2019) 1058-1063.
[39] H.A. Firouzjaie, W.E. Mustain, Catalytic advantages, challenges, and priorities in alkaline membrane fuel cells, ACS Catal. 10 (1) (2020) 225-234.

[40] W.E. Mustain, M. Chatenet, M. Page, Y.S. Kim, Durability challenges of anion exchange membrane fuel cells, Energy Environ. Sci. 13 (9) (2020) 2805-2838.

[41] J. Weiss, H. Zhang, P. Zelenay, Recent progress in the durability of Fe-N-C oxygen reduction electrocatalysts for polymer electrolyte fuel cells, J. Electroanal. Chem. 875 (2020) 114696.

[42] H.W. Kim, M.B. Ross, N. Kornienko, L. Zhang, J. Guo, P. Yang, B.D. McCloskey, Efficient hydrogen peroxide generation using reduced graphene oxide-based oxygen reduction electrocatalysts, Nat. Catal. 1 (4) (2018) 282-290.

[43] T. Jawhari, A. Roid, J. Casado, Raman spectroscopic characterization of some commercially available carbon black materials, Carbon 33 (11) (1995) 1561-1565 N. Y..

[44] A.C. Ferrari, Raman spectroscopy of graphene and graphite: disorder, electron-phonon coupling, doping and nonadiabatic effects, Solid State Commun. $143(1-2)(2007)$ 47-57.

[45] S. Rojas-Carbonell, C. Santoro, A. Serov, P. Atanassov, Transition metal-nitrogen-carbon catalysts for oxygen reduction reaction in neutral electrolyte, Electrochem. commun. 75 (2017) 38-42.

[46] K. Shinozaki, J.W. Zack, R.M. Richards, B.S. Pivovar, S.S. Kocha, Oxygen reduction reaction measurements on platinum electrocatalysts utilizing rotating disk electrode technique, J. Electrochem. Soc. 162 (10) (2015) F1144-F1158.

[47] Z. Wu, L. Li, J.M. Yan, X.B. Zhang, Materials design and system construction for conventional and new-concept supercapacitors, Adv. Sci. 4 (6) (2017) 1600382 $(1-48)$.

[48] S.I. Lee, S. Mitani, C.W. Park, S.H. Yoon, Y. Korai, I. Mochida, Electric double-layer capacitance of microporous carbon nano spheres prepared through precipitation of aromatic resin pitch, J. Power Sources 139 (1-2) (2005) 379-383.

[49] K. Le Van, T.T. Luong Thi, Activated carbon derived from rice husk by $\mathrm{NaOH}$ activation and its application in supercapacitor, Prog. Nat. Sci. Mater. Int. 24 (3) (2014) 191-198

[50] E. Frackowiak, Carbon materials for supercapacitor application, Phys. Chem. Chem. Phys. 9 (15) (2007) 1774-1785.

[51] Y. Guo, J. Qi, Y. Jiang, S. Yang, Z. Wang, H. Xu, Performance of electrical double layer capacitors with porous carbons derived from rice husk, Mater. Chem. Phys. 80 (3) (2003) 704-709.

[52] F. Béguin, V. Presser, A. Balducci, E. Frackowiak, Carbons and electrolytes for advanced supercapacitors, Adv. Mater. 26 (14) (2014) 2219-2251.

[53] S. Taylor, E. Fabbri, P. Levecque, T.J. Schmidt, O. Conrad, The effect of platinum loading and surface morphology on oxygen reduction activity, Electrocatalysis 7 (4) (2016) 287-296.

[54] S. Trasatti, O.A. Petrii, International union of pure and applied chemistry physical chemistry division commission on electrochemistry: real surface area measurements in electrochemistry, Pure Appl. Chem. 63 (5) (1991) 711-734.

[55] U.A. Paulus, T.J. Schmidt, H.A. Gasteiger, R.J. Behm, Oxygen reduction on a high-surface area Pt/Vulcan carbon catalyst: a thin-film rotating ring-disk electrode study, J. Electroanal. Chem. 495 (2) (2001) 134-145.

[56] R. Guidelli, R.G. Compton, J.M. Feliu, E. Gileadi, J. Lipkowski, W. Schmickler, S. Trasatti, Defining the transfer coefficient in electrochemistry: an assessment (IUPAC technical report), Pure Appl. Chem. 86 (2) (2014) 245-258.

[57] A. Holewinski, S. Linic, Elementary mechanisms in electrocatalysis: revisiting the ORR Tafel slope, J. Electrochem. Soc. 159 (11) (2012) H864-H870.

[58] J.X. Wang, N.M. Markovic, R.R. Adzic, Kinetic analysis of oxygen reduction on $\mathrm{Pt}(111)$ in acid solutions: intrinsic kinetic parameters and anion adsorption effects, J. Phys. Chem. B 108 (13) (2004) 4127-4133.

[59] A. Ohma, K. Shinohara, A. Iiyama, T. Yoshida, A. Daimaru, Membrane and catalyst performance targets for automotive fuel cells by FCCJ membrane, catalyst, MEA WG, ECS Trans. 41 (1) (2019) 775-784.

[60] H. Meng, N. Larouche, M. Lefvre, F. Jaouen, B. Stansfield, J.P. Dodelet, Iron porphyrin-based cathode catalysts for polymer electrolyte membrane fuel cells; Effect of $\mathrm{NH}_{3}$ and $\mathrm{Ar}$ mixtures as pyrolysis gases on catalytic activity and stability, Electrochim. Acta 55 (22) (2010) 6450-6461.

[61] X. Zhang, Y. Niu, X. Meng, Y. Li, J. Zhao, Structural evolution and characteristics of the phase transformations between $\alpha-\mathrm{Fe}_{2} \mathrm{O}_{3}, \mathrm{Fe}_{3} \mathrm{O}_{4}$ and $\gamma-\mathrm{Fe}_{2} \mathrm{O}_{3}$ nanoparticles under reducing and oxidizing atmosphere, CrystEngComm 15 (2013) 8166-8172.

[62] A. Mani, T. Kulandaivellu, S. Govindaswamy, A.M. Mohan, $\mathrm{Fe}_{3} \mathrm{O}_{4}$ nanoparticle-encapsulated mesoporous carbon composite: an efficient heterogeneous Fenton catalyst for phenol degradation, Environ. Sci. Pollut. Res. 25 (2018) 20419-20429.

[63] M.M. Mian, G. Liu, B. Yousaf, B. Fu, H. Ullah, M.U. Ali, Q. Abbas, M.A. Mujtaba Munir, L. Ruijia, Simultaneous functionalization and magnetization of biochar via $\mathrm{NH}_{3}$ ambiance pyrolysis for efficient removal of $\mathrm{Cr}$ (VI), Chemosphere 208 (2018) 712-721.

[64] F. Jaouen, S. Marcotte, J.P. Dodelet, G. Lindbergh, Oxygen reduction catalysts for polymer electrolyte fuel cells from the pyrolysis of iron acetate adsorbed on various carbon supports, J. Phys. Chem. B 107 (6) (2003) 1376-1386.

[65] A. Sadezky, H. Muckenhuber, H. Grothe, R. Niessner, U. Pöschl, Raman microspectroscopy of soot and related carbonaceous materials: Spectral analysis and structural information, Carbon 43 (8) (2005) 1731-1742 N. Y.

[66] S. Vollebregt, R. Ishihara, F.D. Tichelaar, Y. Hou, C.I.M. Beenakker, Influence of the growth temperature on the first and second-order Raman band ratios and widths of carbon nanotubes and fibers, Carbon 50 (10) (2012) 3542-3554 N. Y..

[67] X. Yin, H.T. Chung, U. Martinez, L. Lin, K. Artyushkova, P. Zelenay, PGM-Free 
ORR catalysts designed by templating PANI-Type polymers containing functional groups with high affinity to iron, J. Electrochem. Soc. 166 (7) (2019) F3240-F3245

[68] P. Chandran, A. Ghosh, S. Ramaprabhu, High-performance platinum-free oxygen reduction reaction and hydrogen oxidation reaction catalyst in polymer electrolyte membrane fuel cell, Sci. Rep. 8 (1) (2018) 1-11.

[69] U. Martinez, E.F. Holby, S.K. Babu, K. Artyushkova, L. Lin, S. Choudhury, G.M. Purdy, P. Zelenay, Experimental and theoretical trends of PGM-Free electrocatalysts for the oxygen reduction reaction with different transition metals, J. Electrochem. Soc. 166 (7) (2019) F3136-F3142.

[70] M.T. Nguyen, B. Mecheri, A. Iannaci, A. D’Epifanio, S. Licoccia, Iron/Polyindole-based electrocatalysts to enhance oxygen reduction in microbial fuel cells, Electrochim. Acta 190 (2016) 388-395.

[71] M.V. Castegnaro, W.J. Paschoalino, M.R. Fernandes, B. Balke, M.C.M. Alves, E.A. Ticianelli, J. Morais, Pd-M/C ( $\mathrm{M}=\mathrm{Pd}, \mathrm{Cu}, \mathrm{Pt})$ electrocatalysts for oxygen reduction reaction in alkaline medium: correlating the electronic structure with activity, Langmuir 33 (11) (2017) 2734-2743.

[72] C. Santoro, M. Kodali, S. Kabir, F. Soavi, A. Serov, P. Atanassov, Three-dimensional graphene nanosheets as cathode catalysts in standard and supercapacitive microbial fuel cell, J. Power Sources 356 (2017) 371-380.

[73] C. Santoro, A. Serov, R. Gokhale, S. Rojas-Carbonell, L. Stariha, J. Gordon, K. Artyushkova, P. Atanassov, A family of Fe-N-C oxygen reduction electrocatalysts for microbial fuel cell (MFC) application: relationships between surface chemistry and performances, Appl. Catal. B Environ. 205 (2017) 24-33.

[74] I. Merino-Jimenez, C. Santoro, S. Rojas-Carbonell, J. Greenman, I. Ieropoulos, P. Atanassov, Carbon-based air-breathing cathodes for microbial fuel cells, Catalysts 6 (9) (2016) 1-13.

[75] R. Guidelli, R.G. Compton, J.M. Feliu, E. Gileadi, J. Lipkowski, W. Schmickler, S. Trasatti, Definition of the transfer coefficient in electrochemistry (IUPAC Recommendations 2014), Pure Appl. Chem. 86 (2) (2014) 259-262.

[76] J. Perez, E.R. Gonzalez, E.A. Ticianelli, Oxygen electrocatalysis on thin porous coating rotating platinum electrodes, Electrochim. Acta 44 (8-9) (1998) 1329-1339.

[77] T. Shinagawa, A.T. Garcia-Esparza, K. Takanabe, Insight on Tafel slopes from a microkinetic analysis of aqueous electrocatalysis for energy conversion, Sci. Rep. 5 (2015) 1-21 (May).

[78] F. Jaouen, J.P. Dodelet, $\mathrm{O}_{2}$ reduction mechanism on non-noble metal catalysts for PEM fuel cells. Part I: experimental rates of $\mathrm{O}_{2}$ electroreduction, $\mathrm{H}_{2} \mathrm{O}_{2}$ electroreduction, and $\mathrm{H}_{2} \mathrm{O}_{2}$ disproportionation, J. Phys. Chem. C 113 (34) (2009) $15422-15432$

[79] N.M. Markovic, H.A. Gasteiger, P.N. Ross, Oxygen reduction on platinum low-index single-crystal surfaces in sulfuric acid solution. Rotating ring-Pt(hkl) disk studies, J. Phys. Chem. 99 (11) (1995) 3411-3415.

[80] N.M. Marković, H.A. Gasteiger, P.N. Ross, Oxygen reduction on platinum low-index single-crystal surfaces in alkaline solution: rotating ring diskPt(hkl) studies, J. Phys. Chem. 100 (16) (1996) 6715-6721.
[81] A.J. Bard, L.R. Faulkner, Electrochemical Methods: Fundamentals and Applications 2nd ed, Wiley, New York, 2001.

[82] E. Laborda, M.C. Henstridge, C. Batchelor-Mc Auley, R.G. Compton, Asymmetric marcus-Hush theory for voltammetry, Chem. Soc. Rev. 42 (12) (2013) 4894-4905.

[83] L. Osmieri, A.H.A. Monteverde Videla, S. Specchia, The use of different types of reduced graphene oxide in the preparation of $\mathrm{Fe}-\mathrm{N}-\mathrm{C}$ electrocatalysts: capacitive behavior and oxygen reduction reaction activity in alkaline medium, J. Solid State Electrochem. 20 (12) (2016) 3507-3523.

[84] Y. Xu, M.J. Dzara, S. Kabir, S. Pylypenko, K. Neyerlin, A. Zakutayev, X-ray photoelectron spectroscopy and rotating disk electrode measurements of smooth sputtered Fe-N-C films, Appl. Surf. Sci. 515 (2020) 146012 February.

[85] X. Wang, W.T. Zheng, H.W. Tian, S.S. Yu, W. Xu, S.H. Meng, X.D. He, J.C. Han, C.Q. Sun, B.K. Tay, Growth, structural, and magnetic properties of iron nitride thin films deposited by dc magnetron sputtering, Appl. Surf. Sci. 220 (1-4) (2003) 30-39.

[86] R. Gokhale, Y. Chen, A. Serov, K. Artyushkova, P. Atanassov, Novel dual templating approach for preparation of highly active Fe-N-C electrocatalyst for oxygen reduction, Electrochim. Acta 224 (2017) 49-55.

[87] C. Santoro, A. Serov, R. Gokhale, S. Rojas-Carbonell, L. Stariha, J. Gordon, K. Artyushkova, P. Atanassov, A family of Fe-N-C oxygen reduction electrocatalysts for microbial fuel cell (MFC) application: relationships between surface chemistry and performances, Appl. Catal. B Environ. 205 (2017) 24-33.

[88] A. Zitolo, V. Goellner, V. Armel, M.T. Sougrati, T. Mineva, L. Stievano, E. Fonda, F. Jaouen, Identification of catalytic sites for oxygen reduction in iron- and nitrogen-doped graphene materials, Nat. Mater. 14 (9) (2015) 937-942.

[89] G. Huang, L. Yang, X. Ma, J. Jiang, S.H. Yu, H.L. Jiang, Metal-organic framework-templated porous carbon for highly efficient catalysis: the critical role of pyrrolic nitrogen species, Chem.A Eur. J. 22 (10) (2016) 3470-3477.

[90] B.J. Min, H.K. Jeong, Effect of nitrogen doping of graphene oxide on hydrogen and hydroxyl adsorption, J. Korean Phys. Soc. 64 (9) (2014) 1303-1307.

[91] Z. Jiang, Z.J. Jiang, X. Tian, W. Chen, Amine-functionalized holey graphene as a highly active metal-free catalyst for the oxygen reduction reaction, J. Mater. Chem. A 2 (2) (2014) 441-450.

[92] A. Zadick, L. Dubau, N. Sergent, G. Berthomé, M. Chatenet, Huge instability of Pt/C catalysts in alkaline medium, ACS Catal. 5 (8) (2015) 4819-4824.

[93] J. Sanetuntikul, S. Shanmugam, High pressure pyrolyzed non-precious metal oxygen reduction catalysts for alkaline polymer electrolyte membrane fuel cells, Nanoscale 7 (17) (2015) 7644-7650.

[94] P.G. Santori, F.D. Speck, J. Li, A. Zitolo, Q. Jia, S. Mukerjee, S. Cherevko, F. Jaouen, Effect of Pyrolysis atmosphere and electrolyte $\mathrm{pH}$ on the oxygen reduction activity, stability and spectroscopic signature of $\mathrm{FeN}_{\mathrm{x}}$ moieties in $\mathrm{Fe}-\mathrm{N}-\mathrm{C}$ catalysts, J. Electrochem. Soc. 166 (7) (2019) F3311-F3320. 